\title{
Estudio de la percepción de los turistas sobre la calidad del servicio al cliente en la Ciudad de Panamá
}

\section{Miroslava Alzamora de Zárate ${ }^{1, *}$, Vicente Herrera ${ }^{1}$, Donaldo Fong $^{1}$, Yolanda Portillo ${ }^{1}$, Teresa Wong ${ }^{1}$, Kathya Baruco ${ }^{1}$, Rita Melhado $^{1}$, Gisela Ruiz ${ }^{1}$, Joel Del Cid ${ }^{1}$, Alba Justiniani ${ }^{1}$, Lia Córdoba $^{1}$, Salomón Andión ${ }^{1}$ y Eduardo Pazmiño ${ }^{1}$}

${ }_{1}^{1}$ Profesor, Grupo de Investigación de la Facultad de Negocios, Facultad de Negocios, Universidad Santa María la Antigua, Apartado Postal 0819-08550, Panamá, República de Panamá.

*Autor para correspondencia. Email: malzamora@usma.ac.pa

Recibido: 18 de marzo de 2014

Aceptado: 25 de agosto de 2014

\begin{abstract}
In Panama, large economic investments depend on Tourism, therefore, the quality of the attention given to these services is of great importance, in order to assure the sustainability of this sector. This descriptive and transversal study included a survey (based on the SERVQUAL model) designed to assess perception on quality and infrastructure for customer service in Panama, over a sample made of 1664 analyzed tourists. From the applied survey, two factors were marked with lower scores: level of interest on rendering a good service and level of understanding about the needs of the clients. Low training for provision of customer service, as well as low level of English language proficiency by the customer service providers where associated to an overall unfavorable perception from those who were analyzed. This study demonstrates the need for decisive actions, designed to improve the quality of customer service in Panama.
\end{abstract}

Keywords: Customer service, quality of service, tourism, culture, Panama.

\section{Resumen}

Grandes inversiones económicas dependen del sector turismo, por lo que la calidad de atención a estos servicios es de gran importancia para garantizar la sostenibilidad de este sector. El presente estudio, descriptivo transversal, incluyó una encuesta — basada en el modelo SERVQUAL_ para 
Invest. pens. crit.

Vol. 2, No. 4, mayo-agosto 2014.

pp. 4-58

evaluar la percepción de una muestra de 1664 turistas sobre calidad e infraestructuras para el servicio al cliente en Panamá. Los factores que muestran calificaciones más bajas fueron el interés por la prestación de un buen servicio y el entendimiento de las necesidades de los clientes. Poca capacitación para servicio al cliente y un bajo dominio del idioma inglés por parte de los prestadores de servicio estuvieron asociados a la percepción no favorable por parte de los encuestados. El estudio evidencia la necesidad de actuar para mejorar la calidad de servicio al cliente en Panamá.

Palabras clave: Servicio al cliente, calidad de servicio, turismo, cultura, Panamá.

\section{Introducción}

Mediante este trabajo de investigación realizado en la Ciudad de Panamá se aplicó una encuesta a un total de 1,664 turísticas que visitaban el país, durante el mes de diciembre del 2013. El objetivo es medir la percepción de los turistas sobre la calidad de la atención y del servicio al cliente; se pretende reunir en un documento la información necesaria para realizar un diagnóstico de la calidad del servicio y a su vez, presentar recomendaciones y propuestas para la problemática existente.

La realización de este proyecto es de suma importancia tanto para los empresarios como para las personas que laboran en el sector turístico, el gobierno y las empresas relacionadas con el sector servicio, ya que todos se benefician de manera positiva. Si se logra que más turistas quieran venir a visitarnos, sería una realidad si el gobierno, y todos los involucrados aúnen esfuerzos para mejorar el servicio al cliente.

El turismo es, actualmente, una de las actividades económicas, sociales y culturales más importantes con las que puede contar un país o una región. Entendemos por turismo a todas aquellas actividades que tengan que ver con conocer o disfrutar de regiones o espacios en los que uno no vive de manera permanente.

Las cifras turísticas del año 2013, del Departamento de Estadísticas de la Autoridad de Turismo y la Contraloría General muestran que 2.201,854 millones de visitantes entraron a Panamá por los distintos puertos. El crecimiento de $5.6 \%$ es considerado como muy satisfactorio. Se ha tenido el mayor gasto turístico de la región. Las divisas muestran un aporte a nuestra economía de $\$ 3.3$ billones. El crecimiento porcentual del dinero desembolsado por los turistas es del $7.9 \%$ con un incremento real de $\$$ 241.8 con respecto al 2012. El cuadro estadístico que compara el número de visitantes del año 2009 al 2013 señala que en el período de 5 años hubo un crecimiento del $40.9 \%$.

Como consecuencia de los antecedentes presentados, el equipo de profesores, estudiantes y personal directivo de la Facultad de Negocios realiza esta investigación que aportará recomendaciones de utilidad para el crecimiento y desarrollo del sector turístico en Panamá.

\section{Antecedentes}

La importancia de brindar un buen servicio al cliente radica en los siguientes aspectos: 
Invest. pens. crit.

Vol. 2, No. 4, mayo-agosto 2014.

pp. $4-58$

- La competencia es cada vez mayor, cada vez aumenta más el número y la variedad de productos ofertados en el mercado, por lo que se hace necesario ofrecer un valor agregado.

- La competencia es cada vez más dura, los productos se van equiparando en calidad y precio, por lo que se hace necesario buscar una diferenciación.

- Los clientes son cada vez más exigentes, ya no solo buscan calidad y precio, sino también una buena atención, un ambiente agradable, una rápida atención, un trato personalizado.

- Si un cliente queda insatisfecho por el servicio o la atención recibida es muy probable que hable mal de nosotros y cuente su mala experiencia a otros consumidores.

- Si un cliente recibe un buen servicio o atención es muy probable que vuelva a adquirir nuestros productos o vuelva a visitarnos.

- Si un cliente recibe un buen servicio o atención es muy probable que nos recomiende con otros consumidores.

Por todas estas razones, hoy en día, es casi una obligación brindar un servicio excelente al cliente.

El servicio excelente al cliente debe estar presente en todos los aspectos del negocio en donde haya alguna interacción con el ser humano. Debe ir desde el saludo del personal encargado de la seguridad del negocio, hasta los altos niveles jerárquicos de la organización.

Para ello, se debe capacitar a todo el personal, quienes deben estar motivados en brindar una excelente atención al cliente.

La USMA, a través de la Facultad de Negocios, en coordinación con People 1st desarrolló una investigación sobre la percepción del turista sobre la calidad del servicio al cliente. People 1st es una organización británica de capacitación para el sector de hotelería, transporte de pasajeros, viajes y turismo. Trabaja en forma conjunta con los empleadores, el gobierno y los institutos educativos para garantizar el desarrollo de especializaciones de máximo nivel en todos estos sectores mediante el desarrollo de programas de formación, capacitación, información, asesoramiento y orientación. Y para asegurar el aprovechamiento de la inversión pública y privada para apoyar programas que son tan necesarios como reconocidos por empleadores y empleados.

Es necesario señalar que la calidad de servicio es definida como la percepción que tiene el cliente sobre el servicio recibido (Zeithaml y Bitner, 2000). Esta percepción se obtiene de la discrepancia producida entre las expectativas que tenía el cliente antes de recibir el servicio y el desempeño actual. Sin embargo, los clientes no perciben la calidad de servicio como un concepto unidimensional, si no que separan la información en diferentes dimensiones (Zeithaml y Bitner, 2000).

\section{Formulación del problema}

\subsection{Problema general}

Podemos formular el problema de la siguiente manera: 
Invest. pens. crit.

Vol. 2, No. 4, mayo-agosto 2014.

pp. $4-58$

¿Qué percepciones tienen los turistas sobre la calidad de servicio al cliente en la Ciudad de Panamá?

\subsection{Subproblemas}

a. ¿Qué opinan los turistas sobre las infraestructuras locales para la prestación del servicio al cliente?

b. ¿Cómo es el perfil sociodemográfico de los turistas que visitan el país?

c. ¿Qué opinan los turistas sobre sus experiencias con las personas que le han brindado un servicio?

d. ¿Cuándo se puede brindar capacitación en servicio excelente al cliente?

e. ¿Quiénes cuentan con la capacidad científica y experiencia para brindar esta capacitación?

f. ¿Cuál sería el lugar más apropiado para ofrecer esta capacitación?

\section{$\underline{\text { 3. Objetivos }}$}

El objetivo general del estudio es medir las percepciones que tienen los turistas sobre la calidad de servicio al cliente en la Ciudad de Panamá.

Para el logro de este objetivo, se establecieron los siguientes objetivos específicos:

a. Explicar el perfil sociodemográfico de los turistas que visitan el país.

b. Describir qué opinan los turistas sobre las infraestructuras locales para la prestación del servicio al cliente.

c. Describir qué opinan los turistas sobre la calidad de servicio al cliente.

\section{Justificación}

Una investigación sobre el servicio al cliente es de gran importancia para que los turistas quieran viajar a Panamá. El crecimiento de la actividad turística ha incrementado las llegadas, los viajes y los flujos económicos por concepto de servicios turísticos. Sin embargo, se observa la necesidad de brindar una mejor imagen del país a través del servicio excelente a los turistas.

Panamá cuenta con infraestructura suficiente para la prestación de los servicios al turista.; Sin embargo, el tema de la violencia ha venido afectando al sector turístico de tal manera que la participación de cada uno de los actores (hoteleros, agentes de viajes, restaurantes, guías, policía de turismo, transportadores, etc.) no se limita a la práctica del servicio que ofrece, sino que debe contribuir al mejoramiento de la imagen del destino, de la región y del país, especialmente hacia el exterior.

Por ello, una investigación de este tipo, brindará luces sobre las opiniones de los turistas para que a partir de allí, tomar acciones para mejorar la prestación de los servicios en el sector turismo.

\section{Hipótesis}

La hipótesis nula de estudio es la siguiente: 
Invest. pens. crit.

Vol. 2, No. 4, mayo-agosto 2014.

pp. 4-58

Las actitudes de los turistas hacia la calidad del servicio no son percibidas de forma positiva.

La hipótesis de investigación es la siguiente:

Las actitudes de los turistas hacia la calidad del servicio son percibidas de forma positiva.

\section{Lugar del estudio}

Esta investigación se realizó en el área metropolitana de la República de Panamá, a continuación se presenta algunos datos del país.

Localización: La República de Panamá está ubicada entre las siguientes coordenadas: los $7^{\circ} 12^{\prime} 07^{\prime \prime}$ y

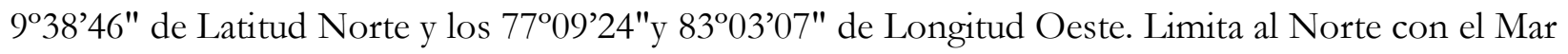
Caribe, al Este con la República de Colombia, al Sur con el Océano Pacífico y al Oeste con la República de Costa Rica.

Organización del Estado Panameño: La Nación Panameña está organizada en Estado Soberano e Independiente, cuya denominación es República de Panamá; su gobierno es unitario, republicano, democrático y representativo.

El Poder Público sólo emana del pueblo, lo ejerce el Estado conforme la Constitución lo establece, por medio de los Órganos Legislativo, Ejecutivo y Judicial, los cuales actúan limitada y separadamente, pero en armónica colaboración.

El territorio de la República de Panamá comprende la superficie terrestre, el mar territorial, la plataforma continental submarina, el subsuelo y el espacio aéreo entre Colombia y Costa Rica, de acuerdo con los tratados de límites celebrados por Panamá con esos Estados.

El español es el idioma oficial de la República.

Moneda: El balboa es la unidad monetaria del país; se subdivide en 100 centésimos y es equivalente al dólar de los Estados Unidos de América.

División Política-Administrativa: Comprende 9 provincias, 75 distritos o municipios, 3 comarcas indígenas (Kuna Yala, Emberá, Ngöbe Buglé), que tienen nivel de provincia, ya que cuentan con un gobernador comarcal; 2 comarcas (Kuna de Madugandí y Kuna de Wargandî) con nivel de corregimiento, con los cuales completan un total de 621 corregimientos en todo el país (2).

Superficie: Total de la República: 75,517km2. Región Metropolitana: 16,777.5 km2 y Resto del País: $58,739.5 \mathrm{~km} 2$. (3)

Mar Territorial: Se extiende a una zona de 12 millas marinas de ancho sobre la cual la República de Panamá ejerce su soberanía, al igual que en el lecho, subsuelo y sobre su espacio aéreo, cuya superficie es de 319,823.9 km2., la cual supera a su territorio continental e insular. 
Invest. pens. crit.

Vol. 2, No. 4, mayo-agosto 2014.

pp. 4-58

Longitud del Litoral: Panamá tiene una considerable longitud de costas, que suman en total, 2,988.3 kilómetros, de los cuales 1,700.6 corresponden al litoral Pacífico; y 1,287.7 al Caribe.

\section{Marco teórico}

Para desarrollar el proyecto de investigación se debe tener en cuenta los siguientes conceptos:

Servicio al cliente es el conjunto de actividades interrelacionadas que ofrece un suministrador con el fin de que el cliente obtenga el producto en el momento y lugar adecuado y se asegure un uso correcto del mismo. El servicio al cliente es una potente herramienta de mercadeo. Se trata de una herramienta que puede ser muy eficaz en una organización si es utilizada de forma adecuada, para ello se deben seguir ciertas políticas institucionales.

Servicio al cliente es "Un concepto de trabajo" y "una forma de hacer las cosas" que compete a toda la organización, tanto en la forma de atender a los Clientes (que nos compran y nos permiten ser viables) como en la forma de atender a los Clientes Internos, diversas áreas de nuestra propia empresa.

ORIENTACION: Conjunto de actividades destinadas a lograr con beneficio la satisfacción del consumidor mediante un producto o servicio dirigido a un mercado con poder adquisitivo, y dispuesto a pagar el precio establecido.

\section{SERVICIO AL CLIENTE}

Muchos diccionarios, inclusive el de la Academia Española de la Lengua definen servicio como una ACTITUD de ayuda de prestación de beneficios, de asistencia, de miramiento, de auxilio, de atención, de complacencia, de cortesía, de cuidado, de consideración, de esmero, de obsequio, de cumplido.

Se puede ver, que existen muchas acepciones a la palabra SERVICIO (diríamos sinónimos) que hacen que ella sea muy amplia.

El servicio cambia la forma de "VER” y “PENSAR” en una organización.

Para hablar de servicio debemos también hablar de calidad; todo lo que implique ésta palabra se debe definir como actitud hacia los demás con servicio, que mejora el encuentro de dos campos sean ellos de cualquier definición.

¿Por qué servir?

Vimos anteriormente que servicio representa una ACTITUD, definida de muchas formas.

SERVIR es brindar a "LA OTRA PERSONA" un cúmulo de comodidades para que su transcurrir sea mejor.

Servir entonces es interactuar con otra (s) persona (s) y generar actitudes positivas que mejoren un transcurrir del momento. 
Invest. pens. crit.

Vol. 2, No. 4, mayo-agosto 2014.

pp. 4-58

De servir se ha hablado en La Sagrada Biblia, en textos de todas las religiones, existen muchos pasajes en donde el servicio ha abierto puertas, ha generado un mejor vivir, ha satisfecho a la otra persona, ha dejado una paz en el alma, ha dejado ese buen sabor de ayudar.

Servir es una actitud de amabilidad, de empatía de decirle a la otra persona "Como te puedo ayudar a mejorar lo que estás haciendo", es conocer las necesidades del otro, es decirle quiero que me tengas en cuenta para que tu desarrollo sea cada vez mejor al igual que el mío.

Primero que no es una actitud soñadora, la de definir el servir de esta forma, es la única manera para lograr desarrollar sistemas que integren a todo los que "tocamos" en nuestro diario trajinar.

En muchas profesiones el servir está implícito, pero ese servir no lo podemos dejar a ellos solamente, en estas épocas el servir, el generar servicio, la siguiente revolución

\section{Reconocimiento de la necesidad de servir}

Es necesario servir la globalización, el convertirse la tierra en una aldea la desarrolla, nuevas tendencias, nuevas políticas, nuevas filosofías y el servir se ha desarrollado cada vez más.

Quien no haga servicio está fuera de foco, se queda atrás y la competencia cada vez es más difícil, desarrollar nuevas técnicas para quedarse con mayor porción de mercado, y obtener el respaldo de sus clientes.

Quien haga del servicio un arma para mejorar sus estrategias con respecto a sus clientes está consiguiendo la ventaja competitiva.

Las organizaciones se están quedando obsoletas por la falta de un modelo consistente o de un marco de referencia para manejar el servicio. Existe en muchos el gran vacío que separa a todos los estamentos.

Los generosos deben observar que ellos mismos son el servicio y este punto de vista se generalizará cada vez más a medida que las competencias sean más fuerte y el servicio se convierta día a día en un arma competitiva. Las gerencias deben ver que dentro del marco del servicio pueden ayudar a los demás a realizar mejor su trabajo; incrementando su cultura creando expectativas de calidad, propiciando un clima de motivación, suministrando los recursos necesarios, ayudando a resolver los problemas, eliminar los obstáculos y están convencidos de que la ejecución de un trabajo de alta calidad da buenos resultados.

\section{CALIDAD DE SERVICIO}

El servicio al cliente se considera como un valor adicional en el caso de productos tangibles y por supuesto, es la esencia en los casos de empresas de servicios. 
Invest. pens. crit.

Vol. 2, No. 4, mayo-agosto 2014.

pp. 4-58

Las empresas se deben caracterizar por el altísimo nivel en la calidad de los servicios que entrega a los clientes que nos compran o contratan. La calidad de los servicios depende de las actitudes de todo el personal de la empresa. El servicio es la solución de un problema o la satisfacción de una necesidad. El personal en todos los niveles y áreas debe ser consciente de que el éxito de las relaciones entre la empresa y cada uno de los clientes depende de las actitudes y conductas que observen en la atención de las demandas de las personas que son o representan al cliente.

Se puede definir calidad en el servicio como: Satisfacer, de conformidad con los requerimientos de cada cliente, las distintas necesidades que tienen y por la que se nos contrató. La calidad se logra a través de todo el proceso de compra, operación y evaluación de los servicios que entregamos. El grado de satisfacción que experimenta el cliente por todas las acciones en las que consiste el mantenimiento en sus diferentes niveles y alcances (Junta de Andalucía, 2010)

La mejor estrategia para conseguir la fidelización de los clientes se logra evitando sorpresas desagradables a los clientes por fallos en el servicio y sorprendiéndolos favorablemente cuando una situación imprevista exija nuestra intervención para superar sus expectativas.

Los compradores o consumidores de algunos productos o servicios, son poco sensibles a la calidad, sin embargo es posible influir en los clientes potenciales y actuales para que aprecien los niveles de calidad en los mismos. Esto se puede lograr mediante la interacción consistente con el cliente para desarrollar un clima de confianza y seguridad por la eliminación de cualquier problemática de funcionamiento, resistencia, durabilidad u otro atributo apreciado por los cliente; esto se puede lograr mediante el aseguramiento de calidad en el servicio y el pleno conocimiento, por parte de los clientes de los mecanismos de gestión de la calidad.

\section{Material y métodos}

\section{Tipo de investigación}

Esta investigación es de tipo descriptiva y de diseño no experimental del tipo transversal. La investigación busca evaluar las opiniones de los turistas sobre la calidad del servicio en Panamá.

\section{Población y muestra}

Para el desarrollo de la presente investigación hemos considerado como elemento de la población, los turistas que visitan el país específicamente en el área metropolitana de Panamá.

Al calcular la muestra se utilizó una fórmula para poblaciones infinitas; en este caso es finita porque no conocemos con precisión cuantos turistas están el país.

$$
\frac{z^{2} p q}{e^{2}}
$$


Invest. pens. crit.

Vol. 2, No. 4, mayo-agosto 2014.

pp. 4-58

La muestra era de: 1067 personas. En este estudio se aplicaron 1,664 encuestas con lo cual se cumplen con creces la cantidad mínima.

\section{Fuentes de información}

En este estudio la recopilación de la información se llevó a cabo mediante fuentes primarias que son las percepciones de los turistas sobres la calidad del servicio al cliente. Para ello, se aplicó un cuestionario necesario para conocer las percepciones de los turistas.

La fuente secundaria estaba compuesta por los libros y documentos relacionados con el servicio al cliente y el crecimiento turístico en Panamá.

$\underline{\text { Variables }}$

Variable independiente: SERVICIO AL CLIENTE.

Es el conjunto de actividades interrelacionadas que ofrece un suministrador con el fin de que el cliente obtenga el producto en el momento y lugar adecuado y se asegure un uso correcto del mismo. El servicio al cliente es una potente herramienta de mercadeo. Se trata de una herramienta que puede ser muy eficaz en una organización si es utilizada de forma adecuada, para ello se deben seguir ciertas políticas institucionales.

Variable dependiente: PERCEPCIONES DE LOS TURISTAS:

Primeramente definiremos la percepción: Obedece a los estímulos cerebrales logrados a través de los 5 sentidos, vista, olfato, tacto, auditivo y gusto, los cuales dan una realidad física del entorno. Es la capacidad de recibir por medio de todos los sentidos, las imágenes, impresiones o sensaciones para conocer algo. También se puede definir como un proceso mediante el cual una persona selecciona, organiza e interpreta los estímulos, para darle un significado a algo. Toda percepción incluye la búsqueda para obtener y procesar cualquier información, de igual manera la asimila y la interioriza para después utilizarla en la vida cotidiana. Para este caso la percepción de los turistas es el conjunto de imágenes y sentido sobre el turismo en Panamá.

Técnicas de recolección de datos

Una encuesta de 35 preguntas, esas preguntas eran de tipo cerradas. La encuesta fue preparada en el idioma español y en el idioma inglés.

Las encuestas fueron aplicadas en los meses de noviembre y diciembre por un grupo de estudiantes de la USMA de los cursos de Servicio al cliente, metodología de investigación y de investigación de mercados. Los lugares visitados fueron: Hoteles, aeropuertos, centros comerciales, y demás lugares turísticos.

\section{$\underline{\text { Procedimiento }}$}

El procedimiento que se utilizó en la investigación fue el siguiente: 
Invest. pens. crit.

Vol. 2, No. 4, mayo-agosto 2014.

pp. 4-58

- Reuniones de las autoridades académicas y personal de la Embajada Británica para conocer el alcance del estudio.

- Documentación preliminar para recopilar toda la información pertinente al tema, lo cual permitió tener una mejor comprensión de los conceptos de actitudes de los turistas y el servicio al cliente.

- Reuniones de coordinación de docentes para crear la encuesta y hacer una prueba piloto de la encuesta.

- Capacitación por parte de los docentes hacia los estudiantes para la realización del trabajo de campo consistente en aplicar la encuesta a turistas que visitan la Ciudad de Panamá.

- Desarrollo del trabajo de campo, con aplicación de encuestas en aeropuertos, hoteles, restaurantes, centros comerciales, entre otros lugares.

- Desarrollo de una base de datos y captura de los datos por parte de un grupo de estudiantes en conjunto con un profesor.

- Cuadros y gráficas sobre los datos y el cruce variables de estudio.

- Discusión de resultados y finalmente, se presentan las conclusiones y recomendaciones que resultan de la presente investigación.

Se procesaron los datos utilizando el programa Statistical Package for the Social Sciences (SPSS 20)

\section{Método para prueba de hipótesis}

Para la prueba de hipótesis se utiliza el coeficiente de correlación producto-momento de Pearson, ya que las variables son medidas en escala numérica. Además, se utiliza la prueba estadística de chi cuadrada $\left(\chi^{2}\right)$, la cual es una prueba estadística para evaluar hipótesis acerca de la relación entre dos variables categóricas.

La chi cuadrada se calcula por medio de una tabla de contingencias o tabulación cruzada, que es una tabla de dos dimensiones y cada dimensión contiene una variable. "La chi cuadrada es una prueba que parte del supuesto de no relación entre variables, y el investigador evalúa sí en su caso esto es cierto o no, analizando si sus frecuencias observadas son diferentes de lo que pudiera esperarse en caso de ausencia de correlación” (Hernández, Fernández y Baptista, 2010, p. 559). Para esta prueba se emplea el SPSS 20, que calcula la Chi-cuadrada $\left(\chi^{2}\right)$ para una tabla de contingencias y determina la probabilidad de que los valores actuales u obtenidos sean diferentes de los valores esperados. El resultado de chi cuadrada se proporciona junto con su significancia, si ésta es menor a .05 se rechaza la hipótesis nula. 
Invest. pens. crit.

Vol. 2, No. 4, mayo-agosto 2014.

pp. 4-58

\section{Resultados}

Información demográfica

A continuación se presenta la información de aspectos demográficos de la muestra de turistas encuestados.

\section{Género}

Como se observa en la Tabla 1, el 53.0\% eran del sexo masculino, un 42.1\% eran del sexo femenino y un $4.9 \%$ no contestaron.

Tabla 1. Género

\begin{tabular}{lcc}
\hline & $\mathrm{f}$ & $\%$ \\
\hline Masculino & 882 & 53.0 \\
Femenino & 701 & 42.1 \\
No contestó & 81 & 4.9 \\
\hline Total & 1664 & 100.0 \\
\hline
\end{tabular}

Fuente: Encuesta aplicada a Turistas en la Ciudad de Panamá, en el mes de noviembre de 2013.

\section{Gráfico 1. Género}

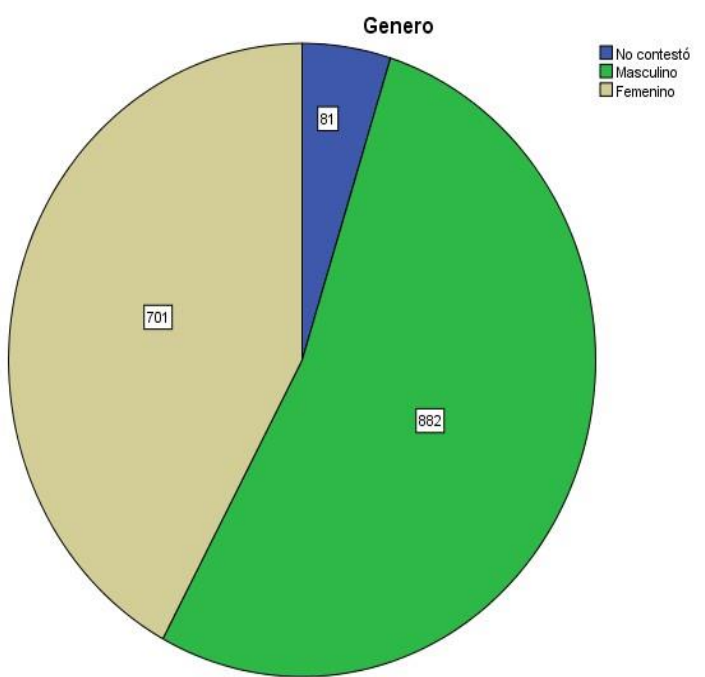

Fuente: Encuesta aplicada a Turistas en la Ciudad de Panamá, en el mes de noviembre de 2013.

\section{Idioma en que contestaron}

En cuanto al idioma en que contestaron, se observa que un $76.0 \%$ contestaron en idioma español y un $24.0 \%$ en idioma inglés.

\begin{tabular}{ccc}
\hline \multicolumn{3}{c}{ Tabla 2. Idioma en que contestó el turista } \\
\hline & $\mathrm{f}$ & $\mathrm{p}$ \\
\hline Español & 1264 & 76.0 \\
Inglés & 400 & 24.0 \\
\hline Total & 1664 & 100.0 \\
\hline
\end{tabular}

Fuente: Encuesta aplicada a Turistas en la Ciudad de Panamá, en el mes de noviembre de 2013. 
Invest. pens. crit.

Vol. 2, No. 4, mayo-agosto 2014.

pp. $4-58$

Gráfico 2. Idioma en que contestó el turista

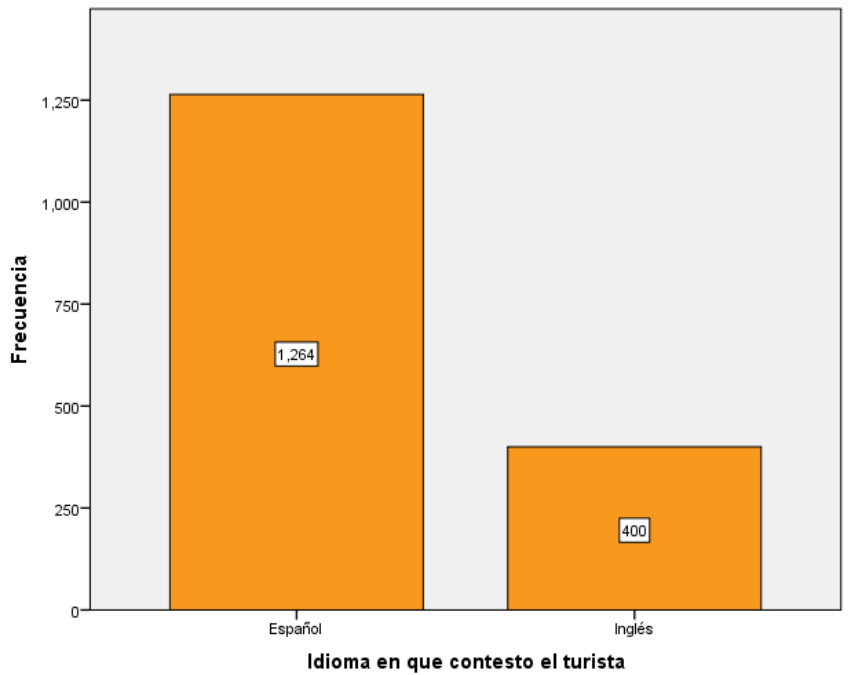

Fuente: Encuesta aplicada a Turistas en la Ciudad de Panamá, en el mes de noviembre de 2013.

\section{Edad}

Como se observa en la Tabla 3, el 36.2\% tenían edades entre 21 a 35 años, un $26.9 \%$ tienen edades entre 36 a 50 años, un 16.2\% tenían 20 o menos años, un 14.4\% tenían edades entre 51 a 65 años, un $5.1 \%$ tenían más de 65 años, y un $1.3 \%$ no contesto.

\begin{tabular}{lcc}
\hline Tabla 3. Edad & & \\
\hline & $\mathrm{f}$ & $\mathrm{p}$ \\
\hline No contestó & 21 & 1.3 \\
20 o menos & 269 & 16.2 \\
De 21 a 35 & 602 & 36.2 \\
De 36 a 50 & 447 & 26.9 \\
De 51 a 65 & 240 & 14.4 \\
Más de 65 & 85 & 5.1 \\
\hline Total & 1664 & 100.0 \\
\hline
\end{tabular}

Fuente: Encuesta aplicada a Turistas en la Ciudad de Panamá, en el mes de noviembre de 2013. 
Invest. pens. crit.

Vol. 2, No. 4, mayo-agosto 2014.

pp. 4-58

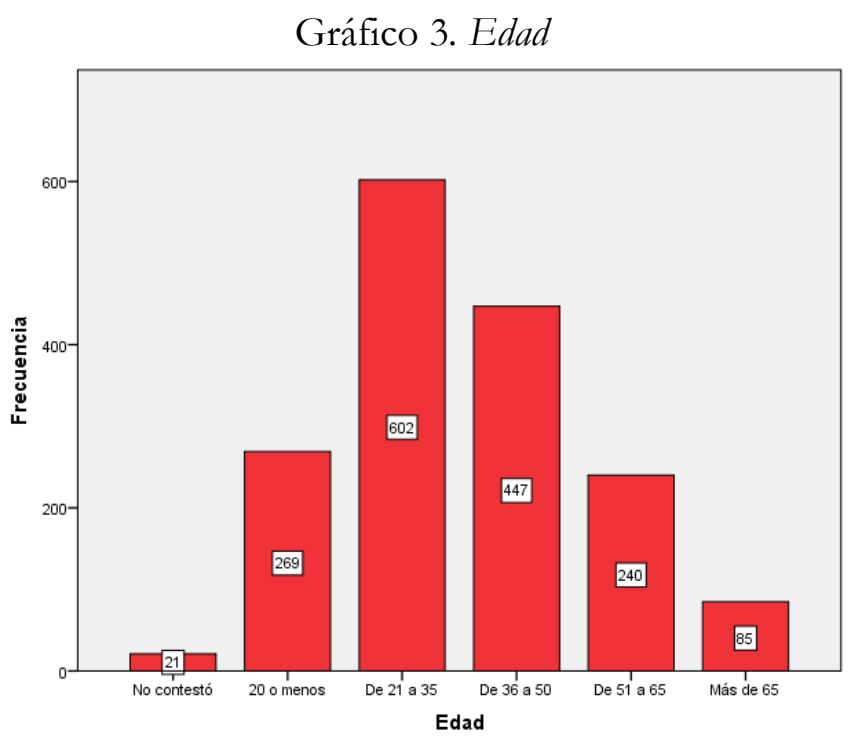

Fuente: Encuesta aplicada a Turistas en la Ciudad de Panamá, en el mes de noviembre de 2013.

\section{Personas que acompañaron al turista}

Como se observa en la Tabla 4, el 48.4\% dijeron que lo acompañan de 2 a 4 personas, un 30.9\% dijeron que viajaban solo, un $10.6 \%$ dijeron que viajaban de 5 o más personas, y un $10.0 \%$ no contestaron.

\begin{tabular}{lcc}
\hline \multicolumn{2}{l}{ Tabla 4. Personas } & \\
\hline \multicolumn{1}{c}{ No contestó } & $\mathrm{f}$ & $\mathrm{P}$ \\
Sólo yo & 5167 & 10.0 \\
2 a 4 & 805 & 30.9 \\
5 o más & 177 & 48.4 \\
\hline \multicolumn{1}{c}{ Total } & 1664 & 10.6 \\
\hline
\end{tabular}

Fuente: Encuesta aplicada a Turistas en la Ciudad de Panamá, en el mes de noviembre de 2013. 
Invest. pens. crit.

Vol. 2, No. 4, mayo-agosto 2014.

pp. 4-58

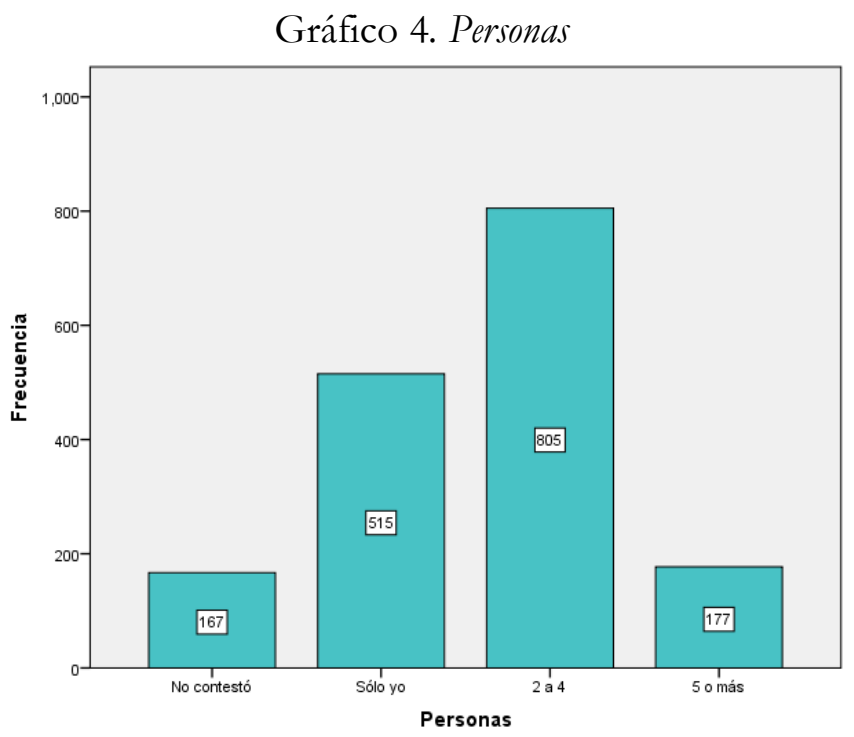

Fuente: Encuesta aplicada a Turistas en la Ciudad de Panamá, en el mes de noviembre de 2013.

\section{Nivel de educación}

En la Tabla 5 se puede ver que el 33.3\% tenían estudios universitarios completo, un 26.2\% están cursando estudios universitarios, un 16.1\% tenían bachilleratos, un 15.4\% tenían maestría completa, un $5.4 \%$ tenían Doctorado, un $2.3 \%$ no contestó y un $1.3 \%$ respondió otros en esta pregunta referenciada al nivel educativo. Más del $50 \%$ son profesionales ya graduados.

\begin{tabular}{lcc}
\hline Tabla 5. Nivel de educación & & \\
\hline & $\mathrm{f}$ & $\mathrm{p}$ \\
\hline No contestó & 38 & 2.3 \\
Bachillerato & 268 & 16.1 \\
Cursando estudios universitarios & 436 & 26.2 \\
Universitario completo & 554 & 33.3 \\
Maestría completa & 257 & 15.4 \\
Doctorado & 90 & 5.4 \\
Otro & 21 & 1.3 \\
\hline Total & 1664 & 100.0 \\
\hline
\end{tabular}

Fuente: Encuesta aplicada a Turistas en la Ciudad de Panamá, en el mes de noviembre de 2013. 
Invest. pens. crit.

Vol. 2, No. 4, mayo-agosto 2014.

pp. 4-58

Gráfico 5. Educación

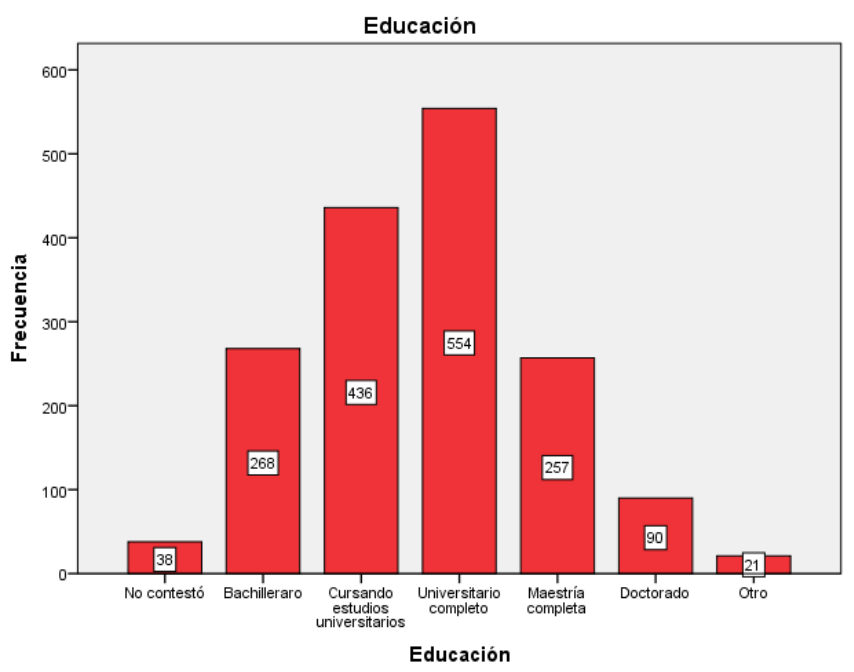

Fuente: Encuesta aplicada a Turistas en la Ciudad de Panamá, en el mes de noviembre de 2013.

\section{Gastos en el último viaje}

En el Cuadro No.6, se aprecia que un 42.1\% gastaron entre $\$ 1,001$ y $\$ 5,000$, un $28.7 \%$ gastaron $\$ 1,000$ o menos, un $14.5 \%$ gastaron entre $\$ 5,001$ y $\$ 10,000$, un $7.5 \%$ no contestó y un $7.3 \%$ gastó más de $\$ 10,000$. Un $78.0 \%$ gastaban de $\$ 5,000$ hacia abajo.

\begin{tabular}{lcc}
\hline Tabla 6. Gastos & & \\
\hline & $\mathrm{f}$ & $\mathrm{p}$ \\
\hline No contestó & 124 & 7.5 \\
\$1000 o menos & 477 & 28.7 \\
Entre $\$ 1,001$ y $\$ 5,000$ & 701 & 42.1 \\
Entre $\$ 5,001$ y $\$ 10,000$ & 241 & 14.5 \\
Más de $\$ 10,000$ & 121 & 7.3 \\
\hline \multicolumn{1}{c}{ Total } & 1664 & 100.0 \\
\hline
\end{tabular}

Fuente: Encuesta aplicada a Turistas en la Ciudad de Panamá, en el mes de noviembre de 2013. 
Invest. pens. crit.

Vol. 2, No. 4, mayo-agosto 2014.

pp. 4-58

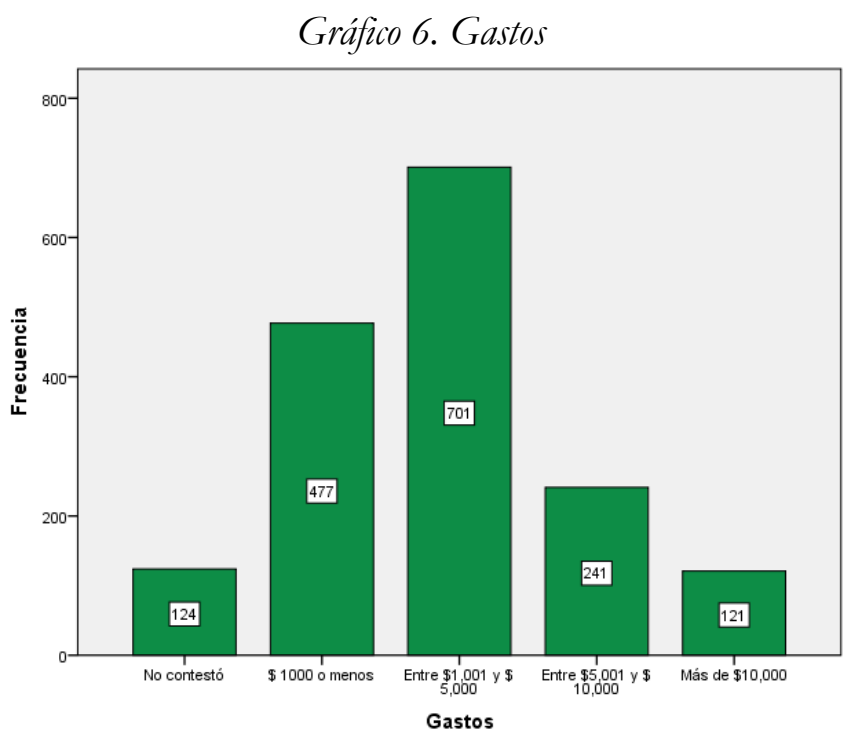

Fuente: Encuesta aplicada a Turistas en la Ciudad de Panamá, en el mes de noviembre de 2013.

\section{Motivo de la visita}

En la Tabla 7, vemos que 45.4\% manifestaron que su motivo de viaje era de placer, un $22.2 \%$ decían que eran de negocios, un 15.3\% decían que era algo personal, un 10.6\% decían que era algo combinado, un $2.9 \%$ no contestó, y un 3.5\% dijo que la respuesta es otro.

\begin{tabular}{lcc}
\hline Tabla 7. Motivo & & \\
\hline & $\mathrm{f}$ & $\mathrm{p}$ \\
\hline No contestó & 49 & 2.9 \\
Placer & 755 & 45.4 \\
Negocio & 370 & 22.2 \\
Personal & 255 & 15.3 \\
Combinado & 177 & 10.6 \\
Otro & 58 & 3.5 \\
\hline Total & 1664 & 100.0
\end{tabular}

Fuente: Encuesta aplicada a Turistas en la Ciudad de Panamá, en el mes de noviembre de 2013. 
Invest. pens. crit.

Vol. 2, No. 4, mayo-agosto 2014.

pp. 4-58

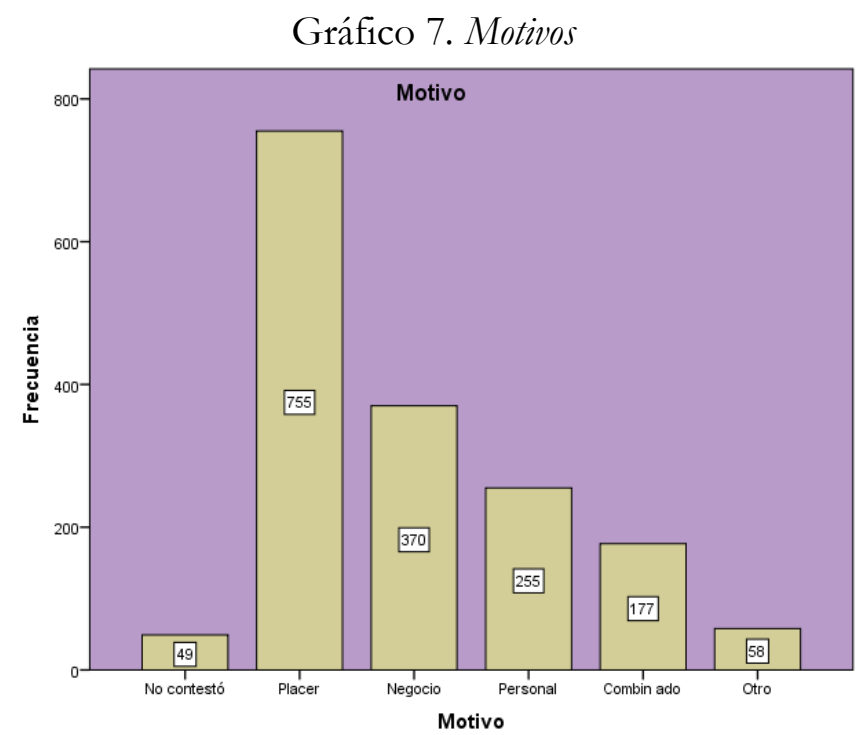

Fuente: Encuesta aplicada a Turistas en la Ciudad de Panamá, en el mes de noviembre de 2013.

\section{Visitas realizadas a Panamá}

En la Tabla 8, se observa que el 36.4\% dicen que han realizado entre 2 a 4 visitas al país, un 34.9\% dijo que sólo una vez, un $13.2 \%$ dice que de 5 a 10 veces, un $9.0 \%$ dice qué más de 10 veces, y un 6.5\% no contestó. Lo anterior denota que más del 50.0\% han regresado nuevamente al país.

\begin{tabular}{lcc}
\hline Tabla 8. Visitas & & \\
\hline & $\mathrm{f}$ & $\mathrm{p}$ \\
\hline No contestó & 108 & 6.5 \\
1 & 581 & 34.9 \\
2 a 4 & 605 & 36.4 \\
5 a 10 & 220 & 13.2 \\
Más de 10 & 150 & 9.0 \\
\hline Total & 1664 & 100.0 \\
\hline
\end{tabular}

Fuente: Encuesta aplicada a Turistas en la Ciudad de Panamá, en el mes de noviembre de 2013. 
Invest. pens. crit.

Vol. 2, No. 4, mayo-agosto 2014.

pp. 4-58

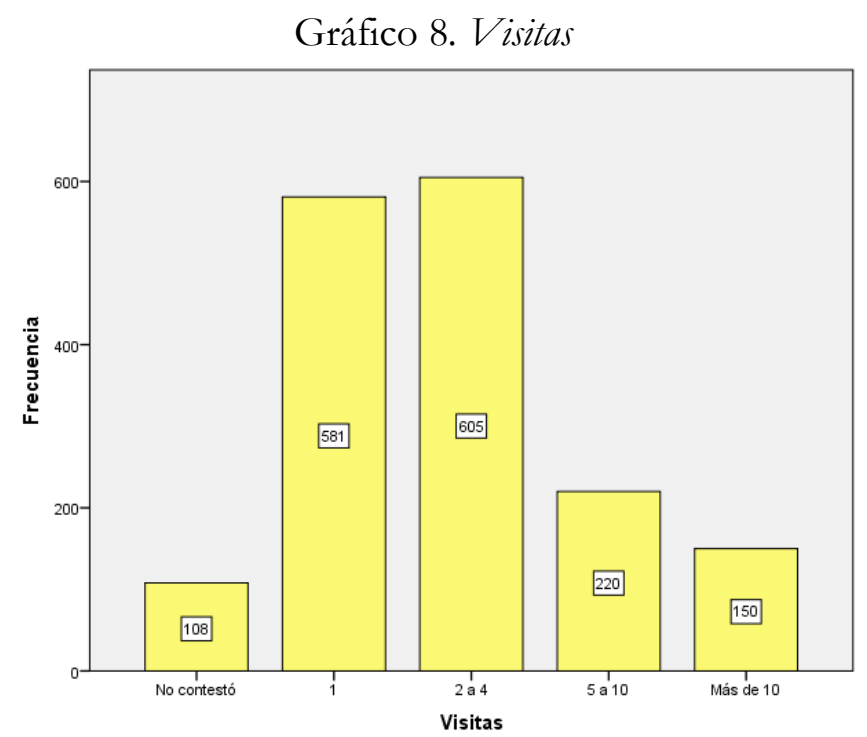

Fuente: Encuesta aplicada a Turistas en la Ciudad de Panamá, en el mes de noviembre de 2013.

País de origen

En cuanto al país de origen, un 47.5\% eran de América Latina, un 24.6\% eran de USA o Canadá, un 14.7\% eran de Europa, un 6.6\% respondieron que eran de otros lugares, un 2.7\% eran de Asia, un $2.6 \%$ no contestó, y un $1.3 \%$ dijeron que eran de Medio Oriente. Lo anterior denota que más del $70.0 \%$ eran del Continente Americano.

\begin{tabular}{lcc}
\hline Tabla 9. Origen & & \\
\hline & $\mathrm{f}$ & $\mathrm{p}$ \\
\hline No contestó & 44 & 2.6 \\
EUA o Canadá & 409 & 24.6 \\
América Latina & 791 & 47.5 \\
Europa & 245 & 14.7 \\
Asia & 45 & 2.7 \\
Medio Oriente & 21 & 1.3 \\
Otro & 109 & 6.6 \\
\hline Total & 1664 & 100.0 \\
\hline
\end{tabular}

Fuente: Encuesta aplicada a Turistas en la Ciudad de Panamá, en el mes de noviembre de 2013. 
Invest. pens. crit.

Vol. 2, No. 4, mayo-agosto 2014.

pp. 4-58

Gráfico 9. Origen

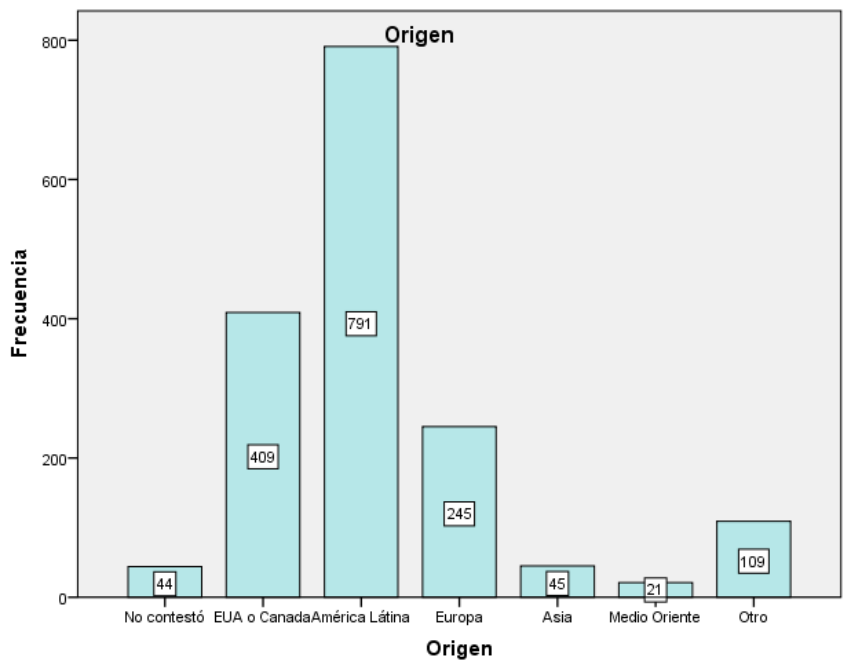

Fuente: Encuesta aplicada a Turistas en la Ciudad de Panamá, en el mes de noviembre de 2013.

Ingresos mensuales familiares

En la Tabla 10, se aprecia que un 27.5\% tenían ingreso de \$3,001 a \$5,000, un 22.6\% tenían ingresos de $\$ 1,501$ a $\$ 3,000$, un $14.5 \%$ gastaron entre $\$ 5,001$ y $\$ 10,000$, un $7.5 \%$ no contestó y un $7.3 \%$ gastó más de $\$ 10,000$. Un 78.0\% gastaban de $\$ 5,000$ hacia abajo.

\begin{tabular}{lcc}
\hline \multicolumn{2}{l}{ Tabla 10. Ingresos } & \\
\hline & $\mathrm{f}$ & $\mathrm{p}$ \\
\hline No contestó & 170 & 10.2 \\
\$1,500 o menos & 374 & 22.5 \\
\$1,501 a \$ 3,000 & 376 & 22.6 \\
\$3,001 a \$ 5,000 & 457 & 27.5 \\
\$5,001 o más & 287 & 17.2 \\
\hline \multicolumn{1}{c}{ Total } & 1664 & 100.0
\end{tabular}

Fuente: Encuesta aplicada a Turistas en la Ciudad de Panamá, en el mes de noviembre de 2013. 
Invest. pens. crit.

Vol. 2, No. 4, mayo-agosto 2014.

pp. 4-58

Gráfico 10. Ingresos

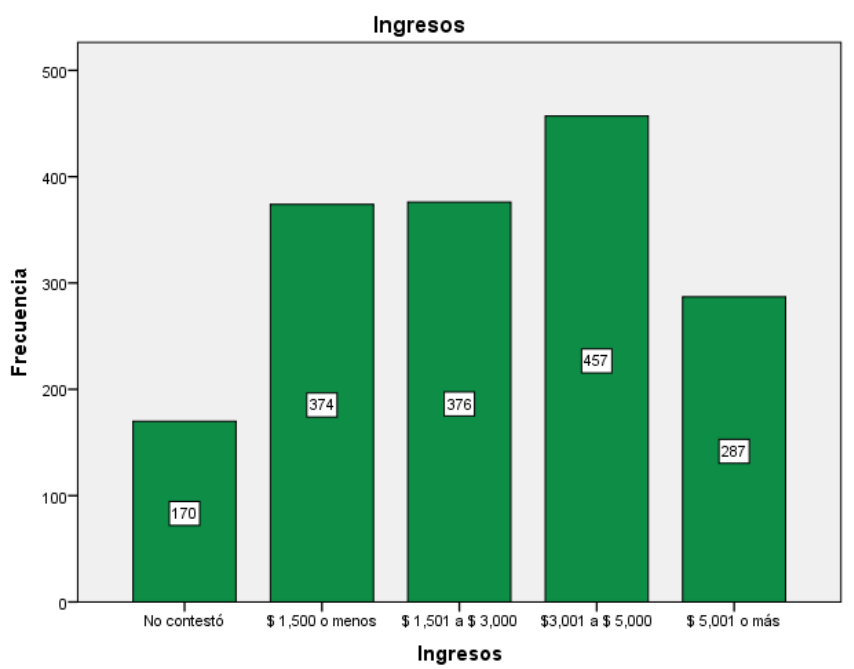

Fuente: Encuesta aplicada a Turistas en la Ciudad de Panamá, en el mes de noviembre de 2013.

\section{Ocupación}

En cuanto a la ocupación, un 22.9\% contestó otros, es decir otras profesiones no colocadas en la encuesta, un $20.5 \%$ eran empresarios, un $20.2 \%$ eran asalariados, un $13.9 \%$ eran ejecutivos de empresa, un $9.1 \%$ son inversionistas, un $8.2 \%$ eran jubilados o retirados, un $5.2 \%$ no contestaron. Lo anterior denota que una tercera parte son empresarios, y el resto son asalariados y jubilados.

\begin{tabular}{lll}
\hline Tabla 11. Ocupación & & \\
\hline & $\mathrm{f}$ & $\mathrm{p}$ \\
\hline No contestó & 86 & 5.2 \\
Ejecutivo de empresa & 232 & 13.9 \\
Inversionista & 152 & 9.1 \\
Empresario & 341 & 20.5 \\
Asalariado & 336 & 20.2 \\
Jubilado/ retirado & 136 & 8.2 \\
Otro & 381 & 22.9 \\
\hline Total & 1664 & 100.0
\end{tabular}

Fuente: Encuesta aplicada a Turistas en la Ciudad de Panamá, en el mes de noviembre de 2013. 
Invest. pens. crit.

Vol. 2, No. 4, mayo-agosto 2014.

pp. $4-58$

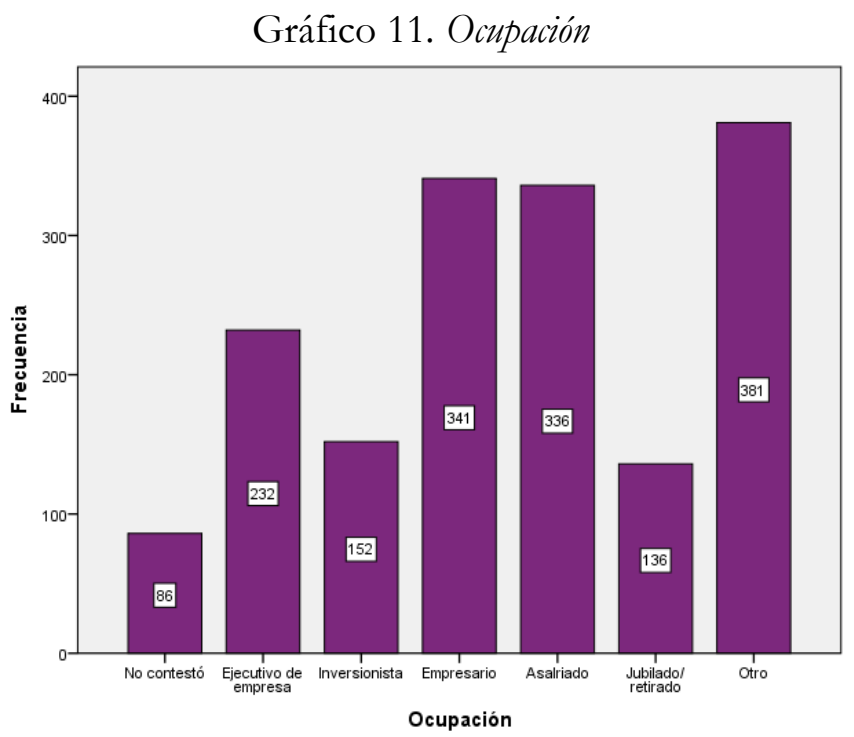

Fuente: Encuesta aplicada a Turistas en la Ciudad de Panamá, en el mes de noviembre de 2013.

Opiniones sobre las infraestructuras turísticas

\section{Panamá como país acogedor}

En la Tabla 12 se puede ver que un 57.3\% (954 personas) contestó que estaban totalmente de acuerdo en que Panamá es un país acogedor para los visitantes, un 27.0\% estaban de acuerdo, un $10.8 \%$ estaban neutrales, un $3.8 \%$ respondieron en desacuerdo, un $1.0 \%$ respondieron en totalmente en desacuerdo, y un $0.1 \%$ no contestaron. Lo anterior nos indica que $84.3 \%$ muestran acuerdo en que Panamá es un país acogedor para los visitantes.

\begin{tabular}{lccc}
\hline \multicolumn{4}{l}{ Tabla 12. Considero que Panamá es un país acogedor para los visitantes } \\
\hline No contestó & $\mathrm{f}$ & $\mathrm{p}$ & $\mathrm{p}$ acumulado \\
\hline Totalmente en desacuerdo & 1 & 0.1 & 0.1 \\
Desacuerdo & 17 & 1.0 & 1.1 \\
Neutral & 64 & 3.8 & 4.9 \\
De acuerdo & 179 & 10.8 & 15.7 \\
Totalmente de acuerdo & 449 & 27.0 & 42.7 \\
\hline Total & 954 & 57.3 & 100.0 \\
\hline
\end{tabular}

Fuente: Encuesta aplicada a Turistas en la Ciudad de Panamá, en el mes de noviembre de 2013. 
Invest. pens. crit.

Vol. 2, No. 4, mayo-agosto 2014.

pp. 4-58

Gráfico 12. Considero que Panamá es un país acogedor para los visitantes

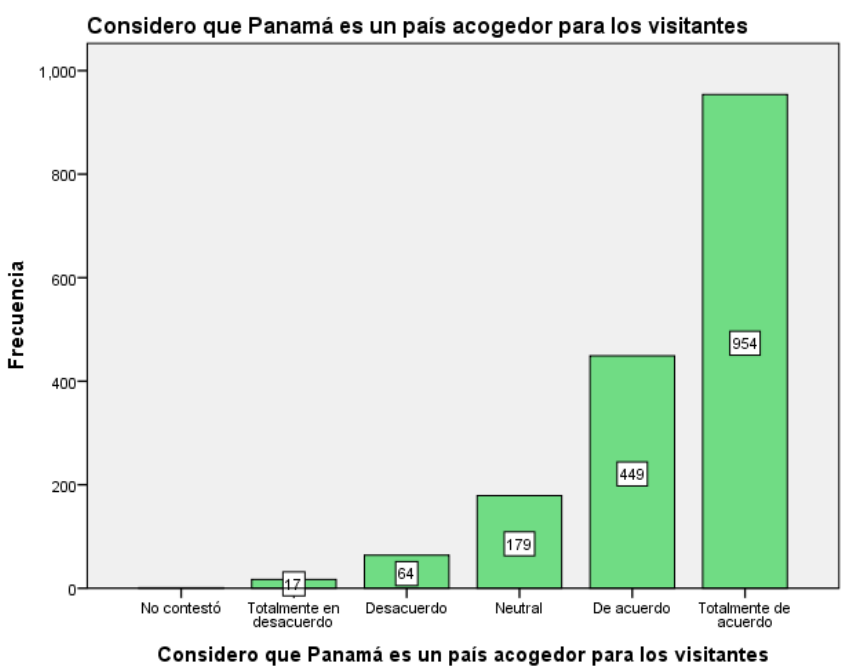

Fuente: Encuesta aplicada a Turistas en la Ciudad de Panamá, en el mes de noviembre de 2013.

\section{Servicios e instalaciones en el Aeropuerto}

En la Tabla 13 se puede ver que un 38.0\% (633 personas) contestó que estaban totalmente de acuerdo en que los servicios e instalaciones en el aeropuerto al llegar o salir son buenos, un 34.8\% estaban de acuerdo, un 20.0\% estaban neutrales, un 4.7\% respondieron en desacuerdo, un 1.8\% respondieron en totalmente en desacuerdo, y un $0.7 \%$ no contestaron. Lo anterior nos indica que $72.8 \%$ muestran acuerdo en que los servicios e instalaciones en el aeropuerto al llegar o salir son buenos, pero hay que mejorar ese aspecto porque hay un $20 \%$ neutrales y existe un desacuerdo del $6.5 \%$.

\begin{tabular}{lccc}
\hline $\begin{array}{l}\text { Tabla 13. Servicios e instalaciones en el aeropuerto al llegar o al salir son } \\
\text { buenos }\end{array}$ & $\mathrm{f}$ & $\mathrm{p}$ & $\mathrm{p}$ acumulado \\
\hline & 12 & 0.7 & 0.7 \\
\hline No contestó & 30 & 1.8 & 2.5 \\
Totalmente en desacuerdo & 78 & 4.7 & 7.2 \\
Desacuerdo & 332 & 20.0 & 27.2 \\
Neutral & 579 & 34.8 & 62.0 \\
De acuerdo & 633 & 38.0 & 100.0 \\
Totalmente de acuerdo & 1664 & 100.0 & \\
\hline Total &
\end{tabular}

Fuente: Encuesta aplicada a Turistas en la Ciudad de Panamá, en el mes de noviembre de 2013. 
Invest. pens. crit.

Vol. 2, No. 4, mayo-agosto 2014.

pp. 4-58

Gráfico 13. Servicios e instalaciones en el aeropuerto al llegar o al salir son buenos

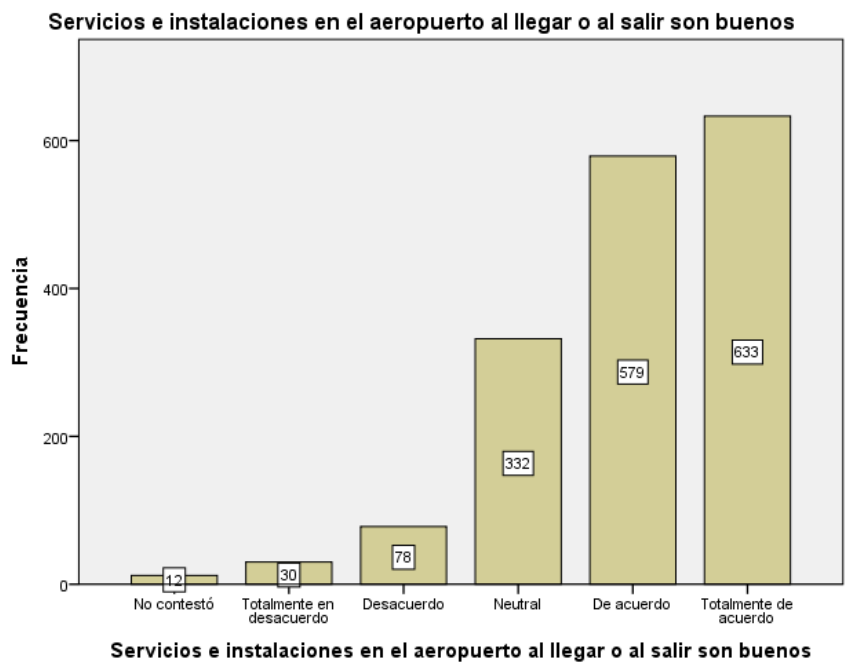

Fuente: Encuesta aplicada a Turistas en la Ciudad de Panamá, en el mes de noviembre de 2013.

\section{Transporte público y selectivo}

En la Tabla 14 se puede ver que un 25.0\% (416 personas) contestó de forma neutral hacia la pregunta el transporte público y selectivo en Panamá es adecuado, un 24.2\% estaban de acuerdo, un $24.0 \%$ estaban totalmente de acuerdo, un $16.9 \%$ respondieron en desacuerdo, un $9.0 \%$ respondieron en totalmente en desacuerdo, y un $0.9 \%$ no contestaron. Lo anterior nos indica que sólo un 48.4\% muestran acuerdo en que el transporte público y selectivo en Panamá es adecuado, esto refleja que se debe mejorar el transporte público y selectivo.

\begin{tabular}{lccc}
\hline $\begin{array}{l}\text { Tabla 14. Transporte público y selectivo en Panamá (taxis, buses) es ade- } \\
\text { cuado }\end{array}$ & $\mathrm{f}$ & $\mathrm{p}$ & $\mathrm{p}$ acumulado \\
\hline & 15 & 0.9 & 0.9 \\
\hline No contestó & 149 & 9.0 & 9.9 \\
Totalmente en desacuerdo & 281 & 16.9 & 26.7 \\
Desacuerdo & 416 & 25.0 & 51.7 \\
Neutral & 403 & 24.2 & 76.0 \\
De acuerdo & 400 & 24.0 & 100.0 \\
Totalmente de acuerdo & 1664 & 100.0 & \\
\hline Total &
\end{tabular}

Fuente: Encuesta aplicada a Turistas en la Ciudad de Panamá, en el mes de noviembre de 2013. 
Invest. pens. crit.

Vol. 2, No. 4, mayo-agosto 2014.

pp. $4-58$

Gráfico 14. Transporte público y selectivo en Panamá (taxis, buses) es adecuado

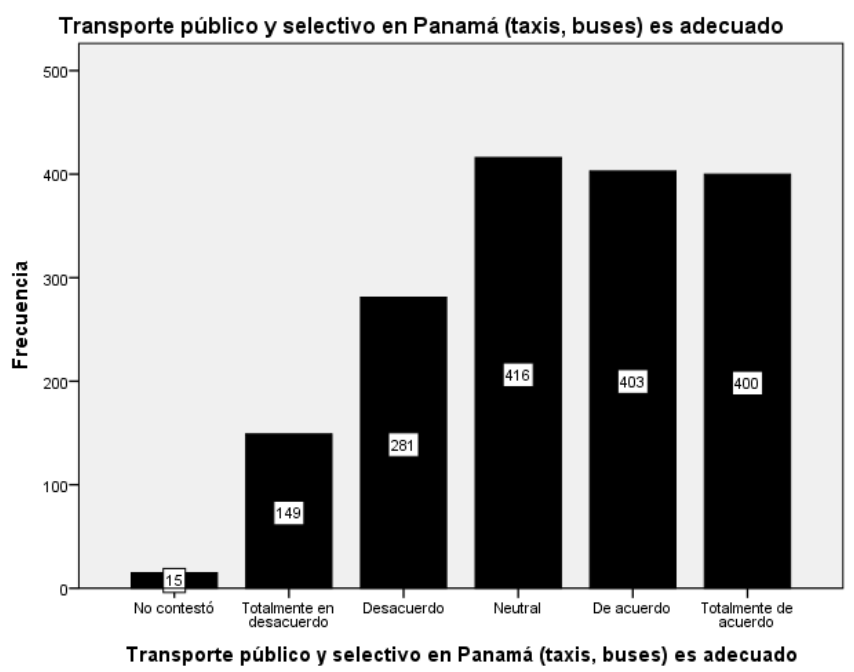

Fuente: Encuesta aplicada a Turistas en la Ciudad de Panamá, en el mes de noviembre de 2013.

\section{Transporte especializado}

En cuanto al transporte especializado se puede ver que un 36.1\% (600 personas) contestó de acuerdo en que el transporte especializado para el turismo son cómodos, un 35.3\% estaban totalmente de acuerdo, un $18.9 \%$ estaban neutrales, un $6.3 \%$ respondieron en desacuerdo, un $2.3 \%$ respondieron en totalmente en desacuerdo, y un 1.1\% no contestaron. Lo anterior nos indica que hay un $71.4 \%$ de acuerdo en que el transporte especializado para el turismo son cómodos, pero aún se puede mejorar con el fin de reducir las respuestas neutrales.

\begin{tabular}{lccc}
\hline \multicolumn{4}{c}{ Tabla 15. Transporte especializado para el turismo son cómodos } \\
\hline \multicolumn{1}{l}{ f } & $\mathrm{p}$ & $\mathrm{p}$ acumulado \\
\hline No contestó & 18 & 1.1 & 1.1 \\
Totalmente en desacuerdo & 39 & 2.3 & 3.4 \\
Desacuerdo & 104 & 6.3 & 9.7 \\
Neutral & 315 & 18.9 & 28.6 \\
De acuerdo & 600 & 36.1 & 64.7 \\
Totalmente de acuerdo & 588 & 35.3 & 100.0 \\
\hline Total & 1664 & 100.0 & \\
\hline Fuente: Encuesta aplicada a Turistas en la Cindad de Panamá, en el mes de noviembre de 2013.
\end{tabular}


Invest. pens. crit.

Vol. 2, No. 4, mayo-agosto 2014.

pp. $4-58$

Gráfico 15. Transporte especializado para el turismo son cómodos

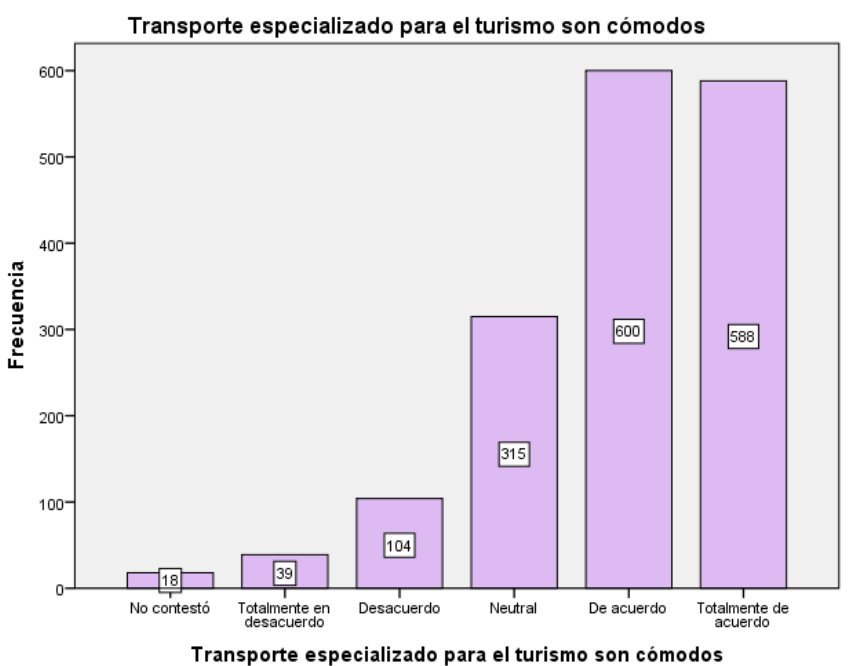

Fuente: Encuesta aplicada a Turistas en la Ciudad de Panamá, en el mes de noviembre de 2013.

Experiencia en hospedajes en hoteles y pensiones

En la Tabla 16, se observa que un 41.2\% (685 personas) contestó totalmente de acuerdo en que la experiencia durante el hospedaje en hoteles y pensiones es buena, un 37.1\% estaban de acuerdo, un $15.6 \%$ estaban neutrales, un $4.4 \%$ respondieron en desacuerdo, un $1.3 \%$ respondieron en totalmente en desacuerdo, y un $0.4 \%$ no contestaron. Lo anterior nos indica que hay un $78.3 \%$ de acuerdo en que la experiencia durante el hospedaje en hoteles y pensiones es buena, pero aún se puede mejorar ese aspecto.

\begin{tabular}{lccc}
\hline \multicolumn{4}{l}{ Tabla 16. Experiencia durante el hospedaje en hoteles y pensiones es buena } \\
\hline & $\mathrm{f}$ & $\mathrm{p}$ & $\mathrm{p}$ acumulado \\
\hline No contestó & 7 & 0.4 & 0.4 \\
Totalmente en desacuerdo & 22 & 1.3 & 1.7 \\
Desacuerdo & 73 & 4.4 & 6.1 \\
Neutral & 260 & 15.6 & 21.8 \\
De acuerdo & 617 & 37.1 & 58.8 \\
Totalmente de acuerdo & 685 & 41.2 & 100.0 \\
\hline Total & 1664 & 100.0 \\
\hline Fuente: Encuesta aplicada a Turistas en la Ciudad de Panamá, en el mes de noviembre de 2013.
\end{tabular}


Invest. pens. crit.

Vol. 2, No. 4, mayo-agosto 2014.

pp. 4-58

Gráfico 16. Experiencia durante el hospedaje en hoteles y pensiones es buena

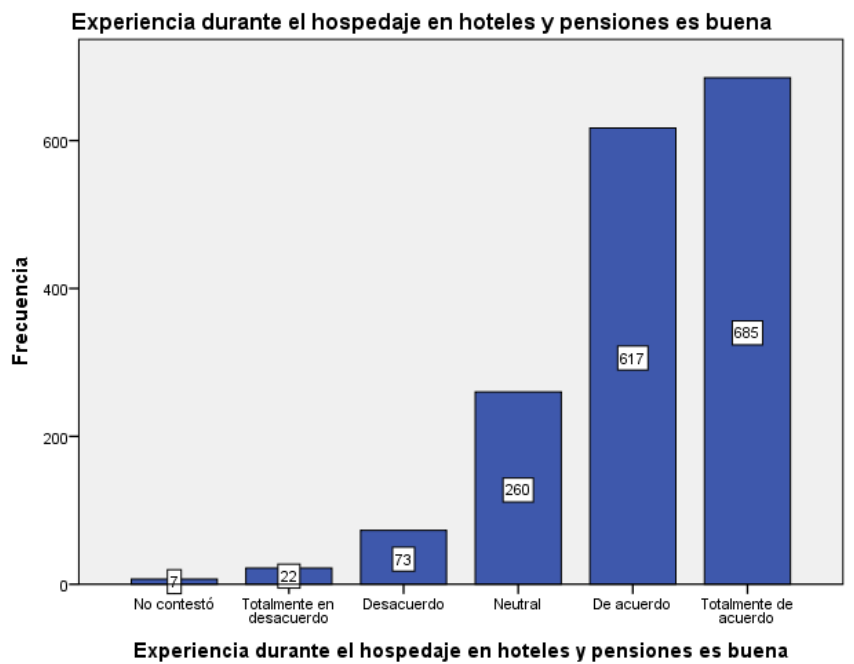

Fuente: Encuesta aplicada a Turistas en la Ciudad de Panamá, en el mes de noviembre de 2013.

Experiencia en los restaurantes

En la Tabla 17, se observa que un 37.2\% (619 personas) contestó totalmente de acuerdo en que la experiencia con los restaurantes y lugares de comida es agradable, un 35.1\% estaban de acuerdo, un $17.6 \%$ estaban neutrales, un $6.6 \%$ respondieron en desacuerdo, un $2.8 \%$ respondieron en totalmente en desacuerdo, y un $0.7 \%$ no contestaron. Lo anterior nos indica que hay un $72.3 \%$ de acuerdo en que la experiencia con los restaurantes y lugares de comida es agradable, pero también ese aspecto se puede mejorar.

\begin{tabular}{|c|c|c|c|}
\hline & $\mathrm{f}$ & $\mathrm{p}$ & $\mathrm{p}$ acumulado \\
\hline No contestó & 12 & 0.7 & 0.7 \\
\hline Totalmente en desacuerdo & 46 & 2.8 & 3.5 \\
\hline Desacuerdo & 110 & 6.6 & 10.1 \\
\hline Neutral & 293 & 17.6 & 27.7 \\
\hline De acuerdo & 584 & 35.1 & 62.8 \\
\hline Totalmente de acuerdo & 619 & 37.2 & 100.0 \\
\hline Total & 1664 & 100.0 & \\
\hline
\end{tabular}


Invest. pens. crit.

Vol. 2, No. 4, mayo-agosto 2014.

pp. 4-58

Gráfico 17. Experiencia con los restaurantes y lugares de comida es agradable

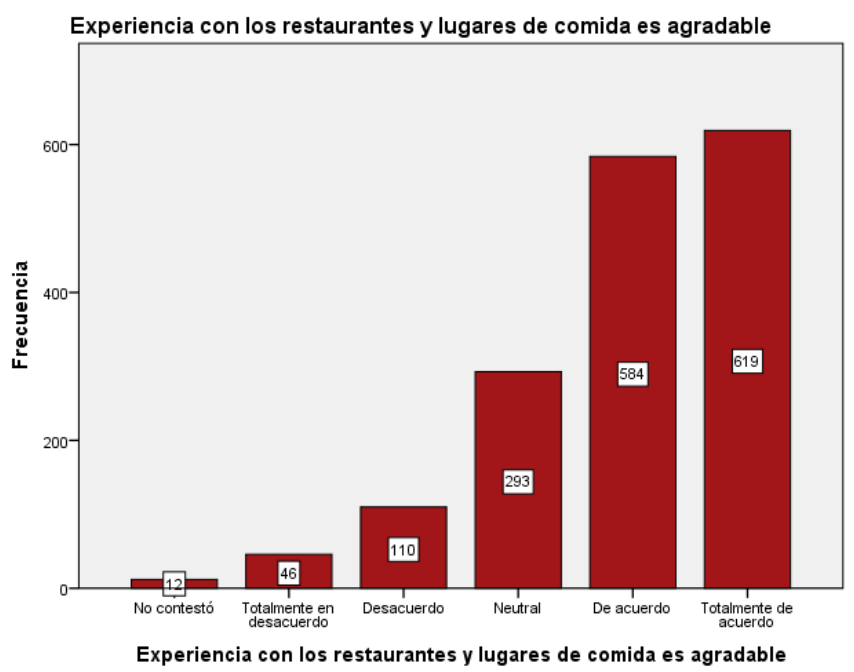

Fuente: Encuesta aplicada a Turistas en la Ciudad de Panamá, en el mes de noviembre de 2013.

Experiencias al hacer compras en Panamá

En cuanto a la experiencia en hacer Compras se puede ver que un 44.8\% (745 personas) contestó totalmente de acuerdo en que la experiencia en hacer compras en Panamá es favorable, un 31.7\% estaban de acuerdo, un 17.2\% estaban neutrales, un 4.3\% respondieron en desacuerdo, un 1.1\% respondieron en totalmente en desacuerdo, y un $0.9 \%$ no contestaron. Lo anterior nos indica que hay un $76.5 \%$ de acuerdo en que la experiencia en hacer compras en Panamá es favorable, pero igual eso se puede mejorar a través de capacitaciones puntuales en materia de servicio al cliente.

\begin{tabular}{lccc}
\hline $\begin{array}{l}\text { Tabla 18. Experiencia en hacer compras en Panamá (como turista) es favo- } \\
\text { rable }\end{array}$ & $\mathrm{f}$ & $\mathrm{p}$ & $\mathrm{p}$ acumulado \\
\hline & 15 & 0.9 & 0.9 \\
\hline No contestó & 18 & 1.1 & 2.0 \\
Totalmente en desacuerdo & 72 & 4.3 & 6.3 \\
Desacuerdo & 286 & 17.2 & 23.5 \\
Neutral & 528 & 31.7 & 55.2 \\
De acuerdo & 745 & 44.8 & 100.0 \\
Totalmente de acuerdo & 1664 & 100.0 & \\
\hline Total &
\end{tabular}

Fuente: Encuesta aplicada a Turistas en la Ciudad de Panamá, en el mes de noviembre de 2013. 
Invest. pens. crit.

Vol. 2, No. 4, mayo-agosto 2014.

pp. 4-58

Gráfico 18. Experiencia en hacer compras en Panamá (como turista) es favorable

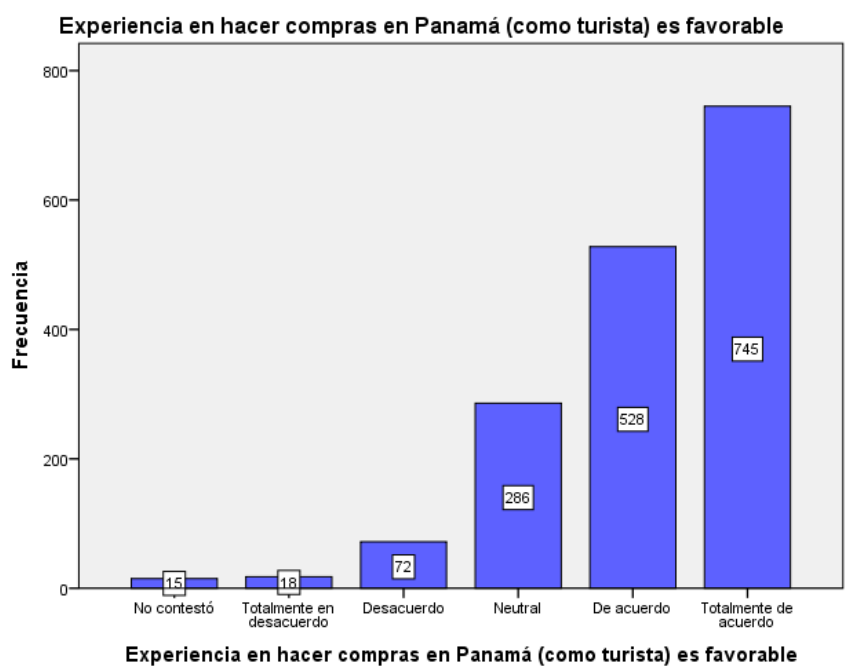

Fuente: Encuesta aplicada a Turistas en la Ciudad de Panamá, en el mes de noviembre de 2013.

\section{Experiencia en visitas a lugares turísticos}

En la Tabla 19 se puede ver que un 45.2\% (752 personas) contestó totalmente de acuerdo en que la experiencia en visitas a lugares turísticos es atractiva, un 32.8\% estaban de acuerdo, un 15.2\% estaban neutrales, un $4.9 \%$ respondieron en desacuerdo, un 1.1\% respondieron en totalmente en desacuerdo, y un $0.7 \%$ no contestaron. Lo anterior nos indica que hay un $78.0 \%$ de acuerdo en que la experiencia en visitas a lugares turísticos es atractiva, pero esto se puede mejorar a través de capacitaciones en materia de servicio al cliente.

\begin{tabular}{|c|c|c|c|}
\hline & $\mathrm{f}$ & $\mathrm{p}$ & $\mathrm{p}$ acumulado \\
\hline No contestó & 12 & 0.7 & 0.7 \\
\hline Totalmente en desacuerdo & 19 & 1.1 & 1.9 \\
\hline Desacuerdo & 82 & 4.9 & 6.8 \\
\hline Neutral & 253 & 15.2 & 22.0 \\
\hline De acuerdo & 546 & 32.8 & 54.8 \\
\hline Totalmente de acuerdo & 752 & 45.2 & 100.0 \\
\hline Total & 1664 & 100.0 & \\
\hline
\end{tabular}


Invest. pens. crit.

Vol. 2, No. 4, mayo-agosto 2014.

pp. $4-58$

Gráfico 19. Experiencia en visitas a lugares turísticos es atractiva

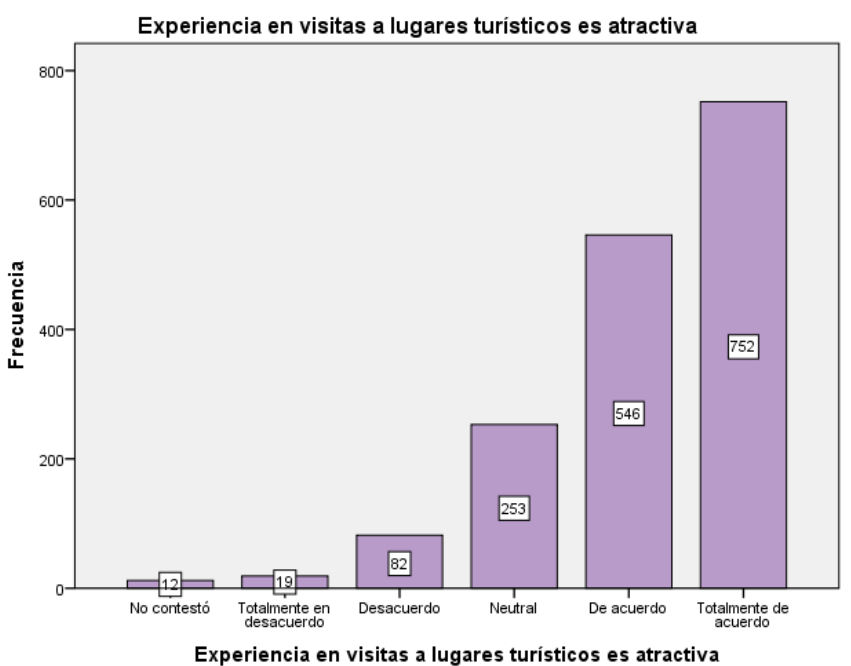

Fuente: Encuesta aplicada a Turistas en la Ciudad de Panamá, en el mes de noviembre de 2013.

\section{Experiencia en percibir aspectos culturales}

En la Tabla 20 se puede ver que un 37.2\% (619 personas) contestó totalmente de acuerdo en que la experiencia en percibir aspectos culturales sobre Panamá es positiva, un 35.6\% estaban de acuerdo, un $20.0 \%$ estaban neutrales, un $4.7 \%$ respondieron en desacuerdo, un $2.0 \%$ respondieron en totalmente en desacuerdo, y un $0.5 \%$ no contestaron. Lo anterior nos indica que hay un $72.8 \%$ de acuerdo en que la experiencia en percibir aspectos culturales sobre Panamá es positiva, también se puede mejorar ese aspecto con capacitaciones en materia de servicio al cliente.

\begin{tabular}{|c|c|c|c|}
\hline \multicolumn{4}{|c|}{$\begin{array}{l}\text { Tabla 20. Experiencia en percibir aspectos culturales sobre Panamá es po- } \\
\text { sitiva }\end{array}$} \\
\hline & $\mathrm{f}$ & $\mathrm{p}$ & p acumulado \\
\hline No contestó & 8 & 0.5 & 0.5 \\
\hline Totalmente en desacuerdo & 34 & 2.0 & 2.5 \\
\hline Desacuerdo & 78 & 4.7 & 7.2 \\
\hline Neutral & 333 & 20.0 & 27.2 \\
\hline De acuerdo & 592 & 35.6 & 62.8 \\
\hline Totalmente de acuerdo & 619 & 37.2 & 100.0 \\
\hline Total & 1664 & 100.0 & \\
\hline
\end{tabular}


Invest. pens. crit.

Vol. 2, No. 4, mayo-agosto 2014.

pp. 4-58

Gráfico 20. Experiencia en percibir aspectos culturales sobre Panamá es positiva

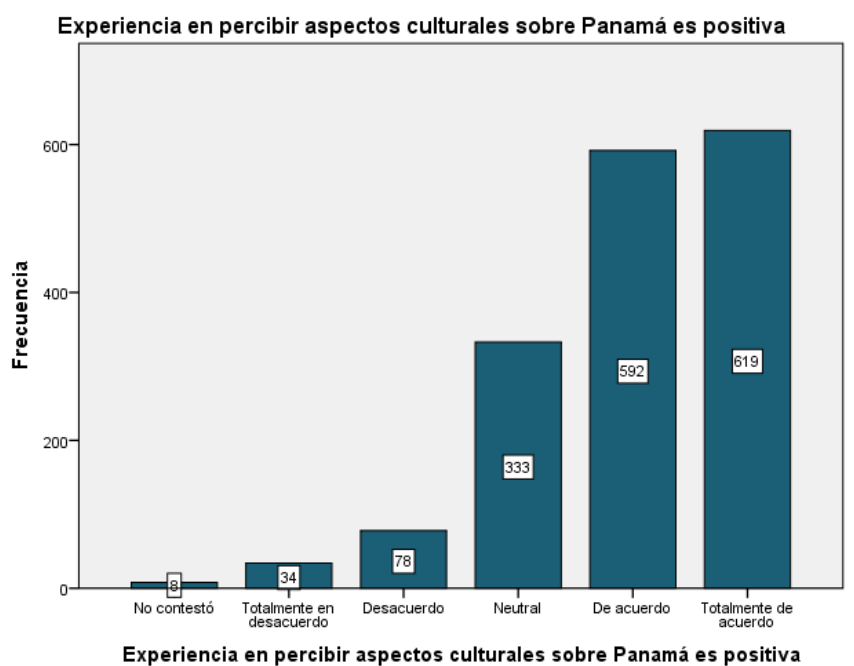

Fuente: Encuesta aplicada a Turistas en la Ciudad de Panamá, en el mes de noviembre de 2013.

\section{Opinión sobre los servicios de telecomunicaciones}

En la Tabla 21 se puede ver que un 35.8\% (595 personas) contestó de acuerdo en que los servicios de telecomunicaciones es buena, un 31.9\% estaban totalmente de acuerdo, un $21.9 \%$ estaban neutrales, un $7.7 \%$ respondieron en desacuerdo, un $2.3 \%$ respondieron en totalmente en desacuerdo, y un $0.5 \%$ no contestaron. Lo anterior nos indica que hay un $77.7 \%$ de acuerdo en que los servicios de telecomunicaciones es buena, pero ese aspecto también se puede mejorar.

\begin{tabular}{|c|c|c|c|}
\hline & $\mathrm{f}$ & $\mathrm{p}$ & $\mathrm{p}$ acumulado \\
\hline No contestó & 8 & 0.5 & 0.5 \\
\hline Totalmente en desacuerdo & 38 & 2.3 & 2.8 \\
\hline Desacuerdo & 128 & 7.7 & 10.5 \\
\hline Neutral & 364 & 21.9 & 32.3 \\
\hline De acuerdo & 595 & 35.8 & 68.1 \\
\hline Totalmente de acuerdo & 531 & 31.9 & 100.0 \\
\hline Total & 1664 & 100.0 & \\
\hline
\end{tabular}

Fuente: Encuesta aplicada a Turistas en la Ciudad de Panamá, en el mes de noviembre de 2013. 
Invest. pens. crit.

Vol. 2, No. 4, mayo-agosto 2014.

pp. $4-58$

Gráfico 21. Servicios de telecomunicaciones (incluye acceso a Internet) es buena

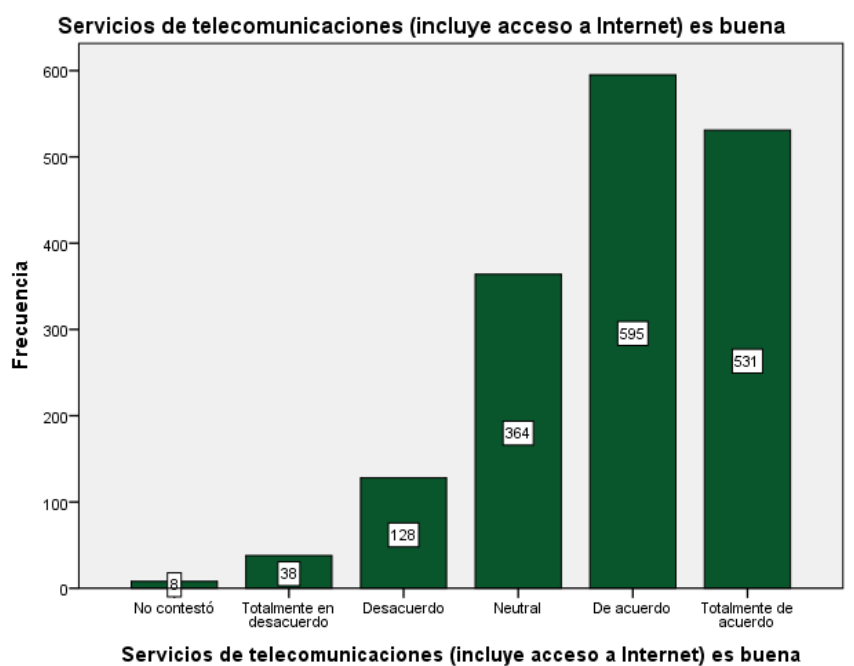

Fuente: Encuesta aplicada a Turistas en la Ciudad de Panamá, en el mes de noviembre de 2013.

\section{Opinión sobre las calles y transporte}

En la Tabla 22 se puede ver que un 25.7\% (428 personas) contestó de forma neutral sobre la infraestructura de calles, transporte y tráfico en general es buena, un $24.5 \%$ estaban de acuerdo, un $20.0 \%$ estaban totalmente de acuerdo, un $17.2 \%$ respondieron en desacuerdo, un $11.7 \%$ respondieron en totalmente en desacuerdo, y un $0.8 \%$ no contestaron. Lo anterior nos indica que sólo hay un $44.5 \%$ de acuerdo en que la infraestructura de calles, transporte y tráfico en general es buena, esto indica que es un factor que se debe mejorar.

\begin{tabular}{|c|c|c|c|}
\hline & $\mathrm{f}$ & $p$ & $\mathrm{p}$ acumulado \\
\hline No contestó & 14 & 0.8 & 0.8 \\
\hline Totalmente en desacuerdo & 195 & 11.7 & 12.6 \\
\hline Desacuerdo & 287 & 17.2 & 29.8 \\
\hline Neutral & 428 & 25.7 & 55.5 \\
\hline De acuerdo & 408 & 24.5 & 80.0 \\
\hline Totalmente de acuerdo & 332 & 20.0 & 100.0 \\
\hline
\end{tabular}

Fuente: Encuesta aplicada a Turistas en la Ciudad de Panamá, en el mes de noviembre de 2013. 
Invest. pens. crit.

Vol. 2, No. 4, mayo-agosto 2014.

pp. $4-58$

Gráfico 22. Infraestructura de calles, transporte y tráfico en general es buena

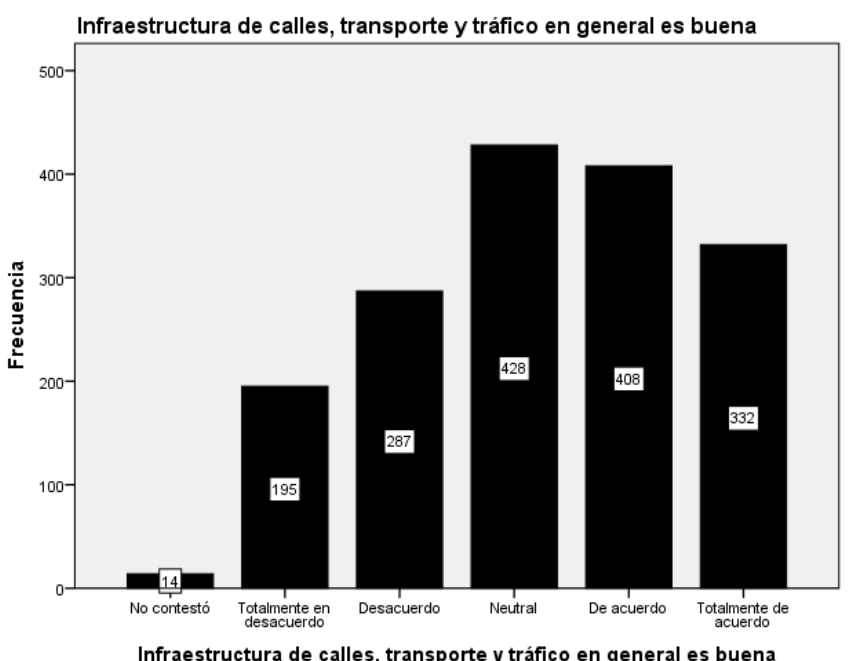

Fuente: Encuesta aplicada a Turistas en la Ciudad de Panamá, en el mes de noviembre de 2013.

\section{Cumplimiento de los objetivos de negocios}

En la Tabla 23 se puede ver que un 32.5\% (540 personas) contestó totalmente de acuerdo sobre si logro completar los objetivos de negocio de forma exitosa, un 31.1\% estaban de acuerdo, un 16.1\% estaban neutral, un 5.6\% respondieron en desacuerdo, un 4.4\% respondieron en totalmente en desacuerdo, y un 10.3\% no contestaron. Lo anterior nos indica que un 63.6\% están de acuerdo en que se logró completar los objetivos de negocio de forma exitosa.

\begin{tabular}{|c|c|c|c|}
\hline & $\mathrm{f}$ & $\mathrm{p}$ & $\mathrm{p}$ acumulado \\
\hline No contestó & 171 & 10.3 & 10.3 \\
\hline Totalmente en desacuerdo & 73 & 4.4 & 14.7 \\
\hline Desacuerdo & 94 & 5.6 & 20.3 \\
\hline Neutral & 268 & 16.1 & 36.4 \\
\hline De acuerdo & 518 & 31.1 & 67.5 \\
\hline Totalmente de acuerdo & 540 & 32.5 & 100.0 \\
\hline Total & 1664 & 100.0 & \\
\hline
\end{tabular}

Fuente: Encuesta aplicada a Turistas en la Ciudad de Panamá, en el mes de noviembre de 2013. 
Invest. pens. crit.

Vol. 2, No. 4, mayo-agosto 2014.

pp. 4-58

Gráfico 23. Logré completar mis objetivos de negocios (si aplica) de forma exitosa

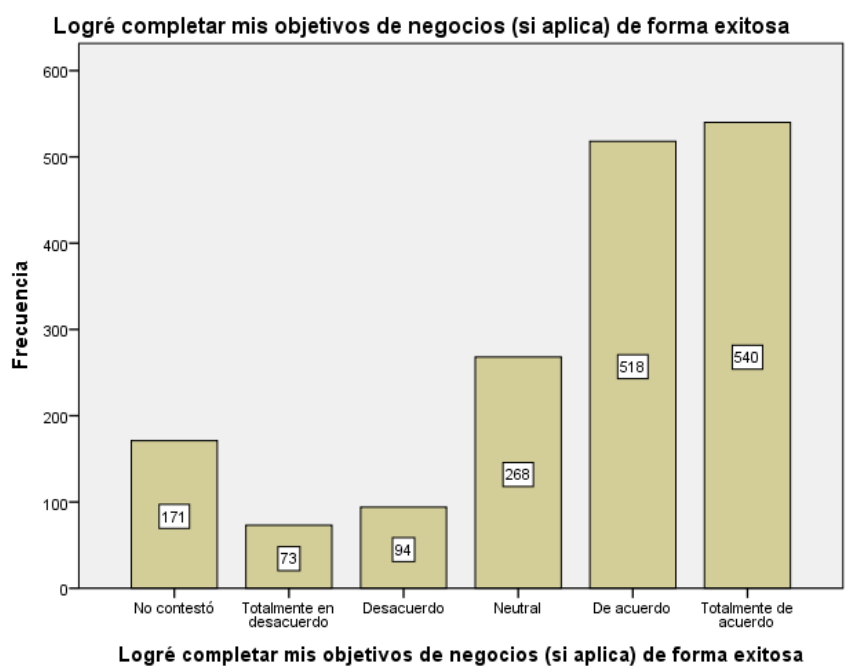

Fuente: Encuesta aplicada a Turistas en la Ciudad de Panamá, en el mes de noviembre de 2013.

$\underline{\text { Información sobre el servicio al cliente }}$

\section{Seguridad en la estadía}

En la Tabla 24 se puede ver que un 38.5\% (640 personas) contestó totalmente de acuerdo en cuanto a la afirmación: me siento seguro durante la estadía de mi visita a Panamá, un 37.8\% estaban de acuerdo, un 16.5\% estaban neutral, un 5.4\% respondieron en desacuerdo, un $1.6 \%$ respondieron en totalmente en desacuerdo, y un $0.2 \%$ no contestaron. Lo anterior nos indica que un $76.3 \%$ están de acuerdo en la afirmación: me siento seguro durante la estadía de mi visita a Panamá, existe casi un $25.0 \%$ que muestran no estar seguros durante la estadía en sus visitas a Panamá.

\begin{tabular}{lccc}
\hline \multicolumn{4}{l}{ Tabla 24. Me siento seguro durante la estadía de mi visita a Panamá } \\
\hline & $\mathrm{f}$ & $\mathrm{p}$ & $\mathrm{p}$ acumulado \\
\hline No contestó & 3 & 0.2 & 0.2 \\
Totalmente en desacuerdo & 27 & 1.6 & 1.8 \\
Desacuerdo & 90 & 5.4 & 7.2 \\
Neutral & 275 & 16.5 & 23.7 \\
De acuerdo & 629 & 37.8 & 61.5 \\
Totalmente de acuerdo & 640 & 38.5 & 100.0 \\
\hline Total & 1664 & 100.0 & \\
\hline
\end{tabular}

Fuente: Encuesta aplicada a Turistas en la Ciudad de Panamá, en el mes de noviembre de 2013. 
Invest. pens. crit.

Vol. 2, No. 4, mayo-agosto 2014.

pp. $4-58$

Gráfico 24. Me siento seguro durante la estadía de mi visita a Panamá

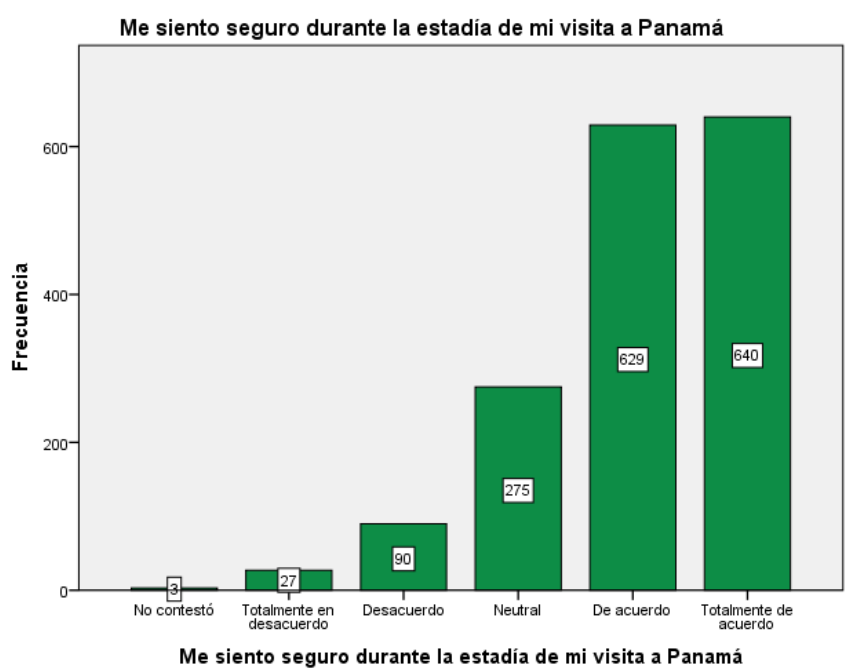

Fuente: Encuesta aplicada a Turistas en la Ciudad de Panamá, en el mes de noviembre de 2013.

\section{Me entienden lo que quiero decir}

En la Tabla 25 se puede ver que un 36.5\% (608 personas) contestó de acuerdo en cuanto a que las personas que le han brindado servicios entienden los que ellos dicen, un 33.4\% estaban totalmente de acuerdo, un $20.6 \%$ estaban neutral, un 5.9\% respondieron en desacuerdo, un 3.2\% respondieron en totalmente en desacuerdo, y un $0.2 \%$ no contestaron. Lo anterior nos indica que un $69.9 \%$ están de acuerdo en que las personas que le han brindado servicios entienden los que ellos dicen, también ese aspecto se puede mejorar a través de la capacitación y formación en el idioma inglés.

\begin{tabular}{|c|c|c|c|}
\hline & $\mathrm{f}$ & $\mathrm{p}$ & $\mathrm{p}$ acumulado \\
\hline No contestó & 4 & 0.2 & 0.2 \\
\hline Totalmente en desacuerdo & 54 & 3.2 & 3.5 \\
\hline Desacuerdo & 99 & 5.9 & 9.4 \\
\hline Neutral & 343 & 20.6 & 30.0 \\
\hline De acuerdo & 608 & 36.5 & 66.6 \\
\hline Totalmente de acuerdo & 556 & 33.4 & 100.0 \\
\hline Total & 1664 & 100.0 & \\
\hline
\end{tabular}


Invest. pens. crit.

Vol. 2, No. 4, mayo-agosto 2014.

pp. $4-58$

Gráfico 25. Las personas que me han brindado servicios entienden lo que les quiero decir

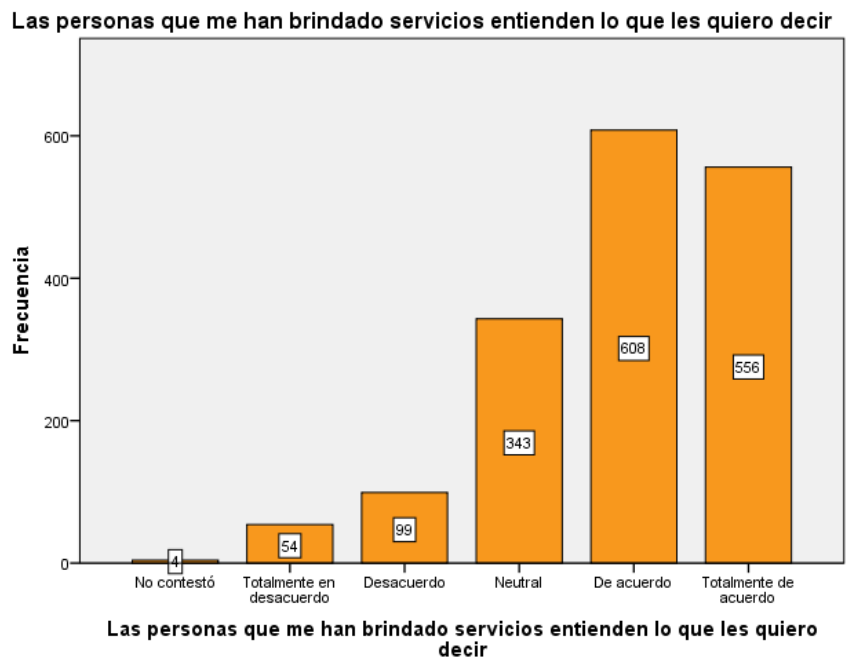

Fuente: Encuesta aplicada a Turistas en la Ciudad de Panamá, en el mes de noviembre de 2013.

\section{Entienden mis necesidades}

En el Cuadro No.26 se puede ver que un 33.9\% (564 personas) contestó de acuerdo en cuanto a que las personas que le han brindado servicios entienden las necesidades como visitante, un 30.6\% estaban totalmente de acuerdo, un $24.6 \%$ estaban neutral, un $7.0 \%$ respondieron en desacuerdo, un $3.3 \%$ respondieron en totalmente en desacuerdo, y un $0.6 \%$ no contestaron. Lo anterior nos indica que un $64.5 \%$ están de acuerdo en que las personas que le han brindado servicios entienden las necesidades como visitante, pero la neutralidad es de $24.6 \%$ lo cual sugiere que debemos mejorar ese aspecto.

\begin{tabular}{|c|c|c|c|}
\hline & $\mathrm{f}$ & $\mathrm{p}$ & $\mathrm{p}$ acumulado \\
\hline No contestó & 10 & 0.6 & 0.6 \\
\hline Totalmente en desacuerdo & 55 & 3.3 & 3.9 \\
\hline Desacuerdo & 116 & 7.0 & 10.9 \\
\hline Neutral & 410 & 24.6 & 35.5 \\
\hline De acuerdo & 564 & 33.9 & 69.4 \\
\hline Totalmente de acuerdo & 509 & 30.6 & 100.0 \\
\hline Total & 1664 & 100.0 & \\
\hline
\end{tabular}

Fuente: Encuesta aplicada a Turistas en la Ciudad de Panamá, en el mes de noviembre de 2013. 
Invest. pens. crit.

Vol. 2, No. 4, mayo-agosto 2014.

pp. 4-58

Gráfico 26. Las personas que me han brindado servicios entienden mis necesidades como visitante

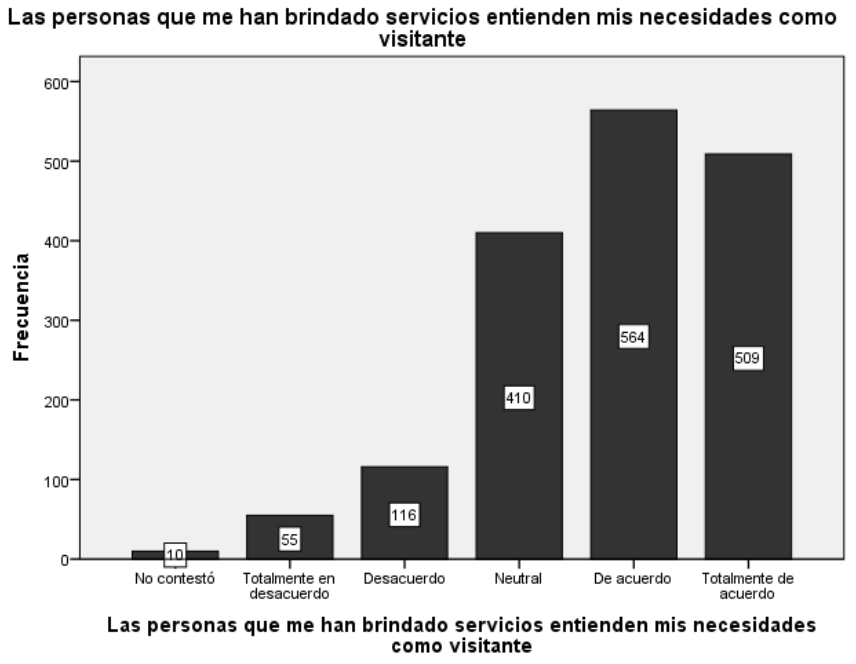

Fuente: Encuesta aplicada a Turistas en la Ciudad de Panamá, en el mes de noviembre de 2013.

\section{Respeto en el trato}

Con respecto al trato se puede ver que un 34.2\% (569 personas) contestó en totalmente de acuerdo en cuanto a que las personas que le han atendido son respetuosos en el trato con ellos, un $32.8 \%$ estaban totalmente de acuerdo, un 23.1\% estaban neutral, un $6.8 \%$ respondieron en desacuerdo, un $3.0 \%$ respondieron en totalmente en desacuerdo, y un $0.1 \%$ no contestaron. Lo anterior nos indica que un $67.0 \%$ están de acuerdo en que las personas que le han brindado servicios entienden las necesidades como visitante, pero la neutralidad es de $23.1 \%$ lo cual sugiere que debemos mejorar ese aspecto.

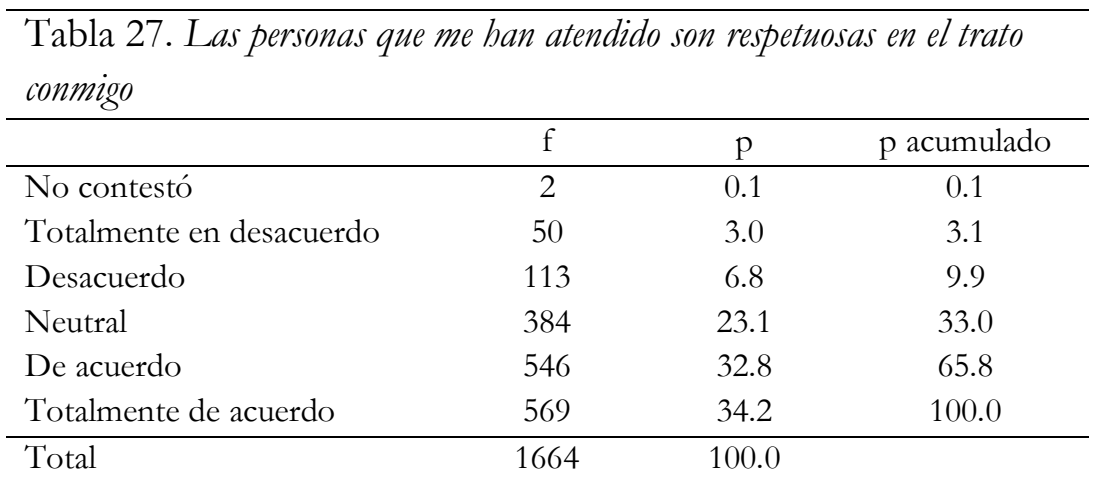

Fuente: Encuesta aplicada a Turistas en la Ciudad de Panamá, en el mes de noviembre de 2013. 
Invest. pens. crit.

Vol. 2, No. 4, mayo-agosto 2014.

pp. 4-58

Gráfico 27. Las personas que me han atendido son respetuosas en el trato conmigo

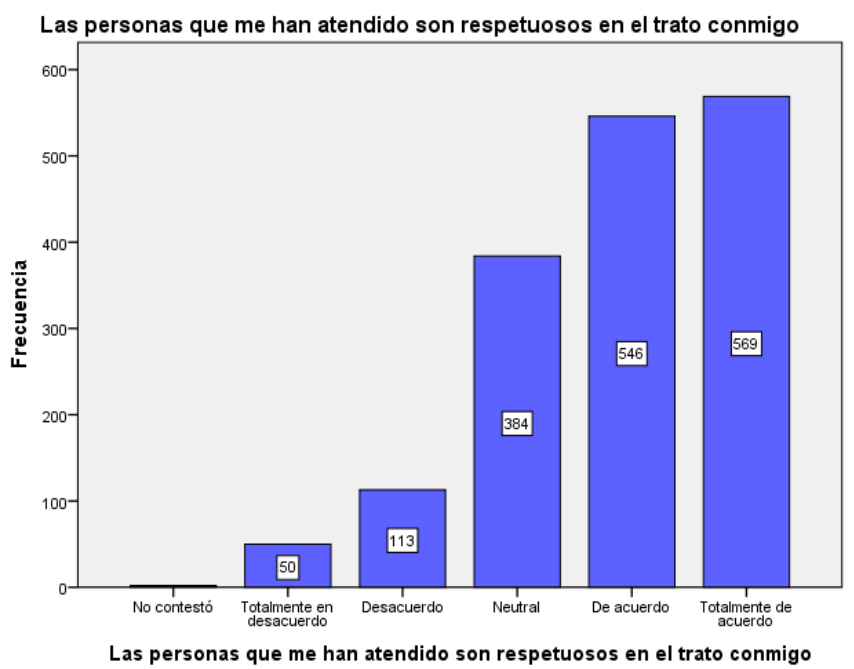

Fuente: Encuesta aplicada a Turistas en la Ciudad de Panamá, en el mes de noviembre de 2013.

\section{Interés en el servicio}

En la Tabla 28 se puede ver que un 34.2\% (569 personas) contestó de acuerdo en que cuando había necesitado algún servicio le demostraron interés sincero en solucionarlo, un $29.8 \%$ estaban totalmente de acuerdo, un $24.2 \%$ estaban neutral, un $7.8 \%$ respondieron en desacuerdo, un 3.8\% respondieron en totalmente en desacuerdo, y un $0.2 \%$ no contestaron. Lo anterior nos indica que un $64.0 \%$ están de acuerdo en que cuando había necesitado algún servicio le demostraron interés sincero en solucionarlo, pero la neutralidad es de $24.2 \%$ lo cual sugiere que se puede mejorar eso a través de la capacitación en servicio al cliente.

\begin{tabular}{|c|c|c|c|}
\hline \multicolumn{4}{|c|}{$\begin{array}{l}\text { Tabla 28. Cuando he necesitado algún servicio me han mostrado interés } \\
\text { sincero en solucionarlo }\end{array}$} \\
\hline & $\mathrm{f}$ & $\mathrm{p}$ & $\mathrm{p}$ acumulado \\
\hline No contestó & 3 & 0.2 & 0.2 \\
\hline Totalmente en desacuerdo & 63 & 3.8 & 4.0 \\
\hline Desacuerdo & 130 & 7.8 & 11.8 \\
\hline Neutral & 403 & 24.2 & 36.0 \\
\hline De acuerdo & 569 & 34.2 & 70.2 \\
\hline Totalmente de acuerdo & 496 & 29.8 & 100.0 \\
\hline Total & 1664 & 100.0 & \\
\hline
\end{tabular}

Fuente: Encuesta aplicada a Turistas en la Ciudad de Panamá, en el mes de noviembre de 2013. 
Invest. pens. crit.

Vol. 2, No. 4, mayo-agosto 2014.

pp. $4-58$

Gráfico 28. Cuando he necesitado algún servicio me han mostrado interés sincero en solucionarlo

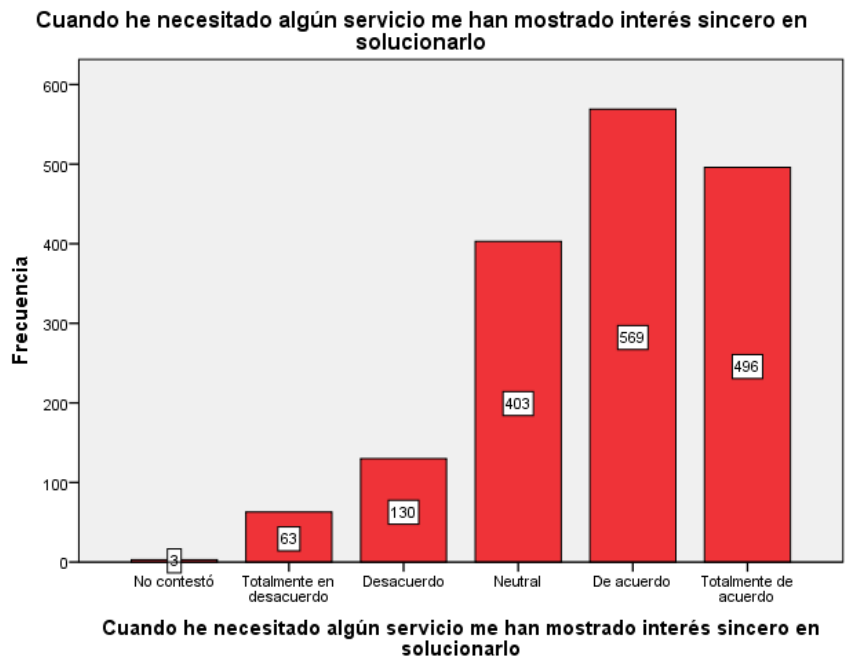

Fuente: Encuesta aplicada a Turistas en la Ciudad de Panamá, en el mes de noviembre de 2013.

\section{Amabilidad de la gente}

En la Tabla 29 se puede ver que un 33.2\% (553 personas) contestó de acuerdo en que la gente de la calle es amable y los ayudo a orientarse o llegar a su destino, un 32.0\% estaban totalmente de acuerdo, un $23.4 \%$ estaban neutral, un 7.5 respondieron en desacuerdo, un $3.3 \%$ respondieron en totalmente en desacuerdo, y un $0.5 \%$ no contestaron. Lo anterior nos indica que un $65.2 \%$ están de acuerdo en que la gente de la calle es amable y los ayudo a orientarse o llegar a su destino, pero la neutralidad es alta de un 23.4\% lo cual sugiere que se puede mejorar eso a través de la capacitación en una cultura de servicio al cliente.

\begin{tabular}{|c|c|c|c|}
\hline & $\mathrm{f}$ & $\mathrm{p}$ & $\mathrm{p}$ acumulado \\
\hline No contestó & 9 & 0.5 & 0.5 \\
\hline Totalmente en desacuerdo & 55 & 3.3 & 3.8 \\
\hline Desacuerdo & 125 & 7.5 & 11.4 \\
\hline Neutral & 389 & 23.4 & 34.7 \\
\hline De acuerdo & 553 & 33.2 & 68.0 \\
\hline Totalmente de acuerdo & 533 & 32.0 & 100.0 \\
\hline Total & 1664 & 100.0 & \\
\hline
\end{tabular}

Fuente: Encuesta aplicada a Turistas en la Ciudad de Panamá, en el mes de noviembre de 2013. 
Invest. pens. crit.

Vol. 2, No. 4, mayo-agosto 2014.

pp. 4-58

Gráfico 29. La gente de la calle es amable y me ayudó en orientarme o llegar a mis destinos

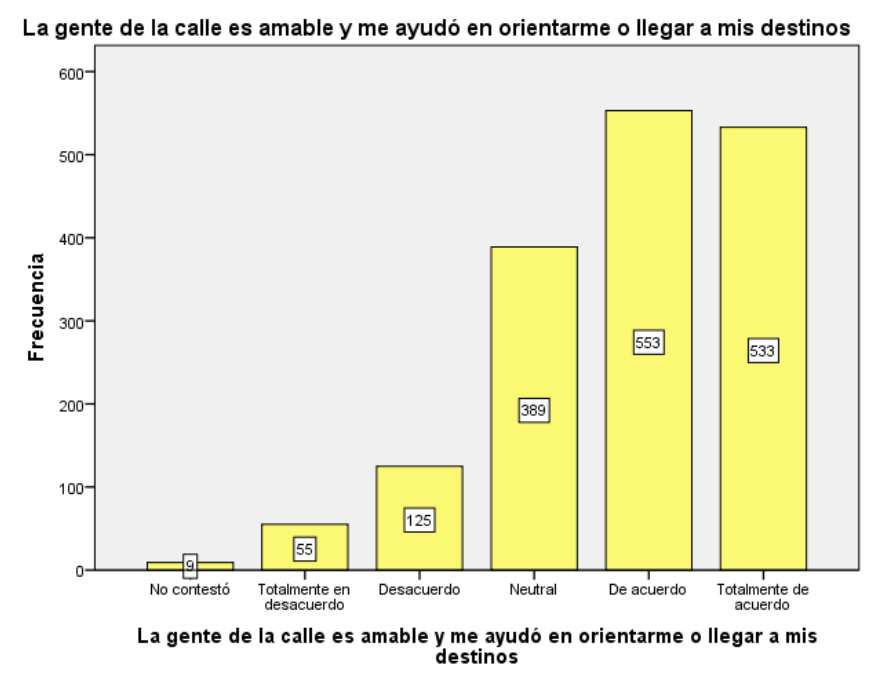

Fuente: Encuesta aplicada a Turistas en la Ciudad de Panamá, en el mes de noviembre de 2013.

\section{Atención a tiempo}

En la Tabla 30 se puede ver que un 36.1\% (601 personas) contestó de acuerdo en que ha sido atendido a tiempo en sus necesidades relacionadas con su visita, un $29.7 \%$ estaban totalmente de acuerdo, un $23.9 \%$ estaban neutral, un $6.6 \%$ respondieron en desacuerdo, un 3.2\% respondieron en totalmente en desacuerdo, y un $0.4 \%$ no contestaron. Lo anterior nos indica que un $65.8 \%$ están de acuerdo en que ha sido atendido a tiempo en sus necesidades relacionadas con su visita, pero la neutralidad es alta de un $23.9 \%$ lo cual sugiere que se puede mejorar eso a través de la capacitación en una cultura de servicio al cliente.

\begin{tabular}{|c|c|c|c|}
\hline & $\mathrm{f}$ & $\mathrm{p}$ & $\mathrm{p}$ acumulado \\
\hline No contestó & 7 & 0.4 & 0.4 \\
\hline Totalmente en desacuerdo & 54 & 3.2 & 3.7 \\
\hline Desacuerdo & 110 & 6.6 & 10.3 \\
\hline Neutral & 397 & 23.9 & 34.1 \\
\hline De acuerdo & 601 & 36.1 & 70.3 \\
\hline Totalmente de acuerdo & 495 & 29.7 & 100.0 \\
\hline Total & 1664 & 100.0 & \\
\hline
\end{tabular}

Fuente: Encuesta aplicada a Turistas en la Ciudad de Panamá, en el mes de noviembre de 2013. 
Invest. pens. crit.

Vol. 2, No. 4, mayo-agosto 2014.

pp. $4-58$

Gráfico 30. He sido atendido a tiempo en mis necesidades relacionados a mi visita

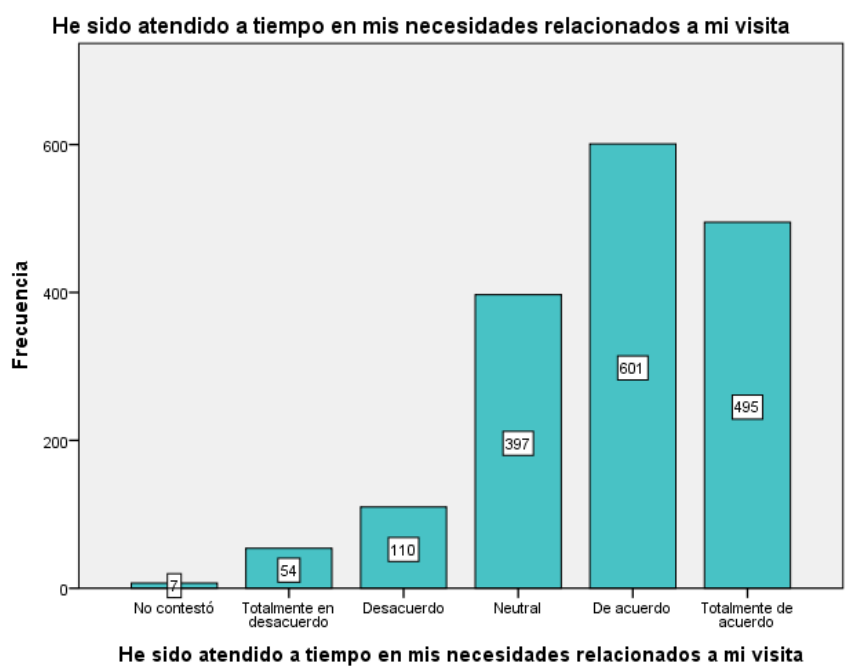

Fuente: Encuesta aplicada a Turistas en la Ciudad de Panamá, en el mes de noviembre de 2013.

\section{Me han brindado un buen servicio}

En la Tabla 31 se puede ver que un 33.2\% (552 personas) contestó en totalmente de acuerdo en que las personas le han dado un buen servicio desde la primera vez, un 32.2\% estaban de acuerdo, un $23.6 \%$ estaban neutral, un $7.2 \%$ respondieron en desacuerdo, un 3.5\% respondieron en totalmente en desacuerdo, y un $0.4 \%$ no contestaron. Lo anterior nos indica que un $65.4 \%$ están de acuerdo en que las personas le han dado un buen servicio desde la primera vez, pero la neutralidad es alta de un $23.6 \%$ lo cual sugiere que se puede mejorar eso a través de la capacitación en una cultura de servicio al cliente.

\begin{tabular}{|c|c|c|c|}
\hline & $\mathrm{f}$ & $\mathrm{p}$ & $\mathrm{p}$ acumulado \\
\hline No contestó & 6 & 0.4 & 0.4 \\
\hline Totalmente en desacuerdo & 59 & 3.5 & 3.9 \\
\hline Desacuerdo & 119 & 7.2 & 11.1 \\
\hline Neutral & 392 & 23.6 & 34.6 \\
\hline De acuerdo & 536 & 32.2 & 66.8 \\
\hline Totalmente de acuerdo & 552 & 33.2 & 100.0 \\
\hline Total & 1664 & 100.0 & \\
\hline
\end{tabular}

Fuente: Encuesta aplicada a Turistas en la Ciudad de Panamá, en el mes de noviembre de 2013. 
Invest. pens. crit.

Vol. 2, No. 4, mayo-agosto 2014.

pp. $4-58$

Gráfico 31. Las personas que me han atendido me han dado un buen servicio desde la primera vez.

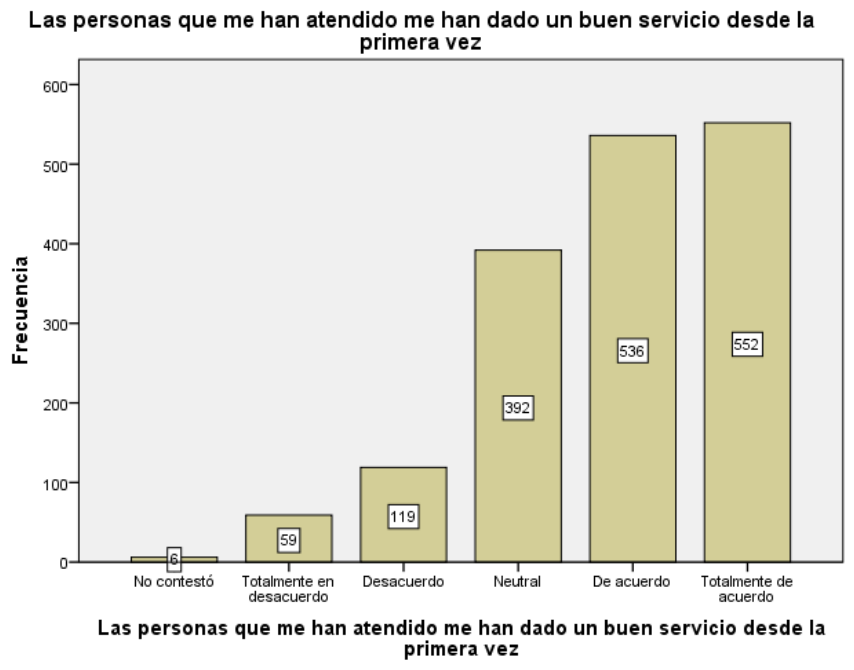

Fuente: Encuesta aplicada a Turistas en la Ciudad de Panamá, en el mes de noviembre de 2013.

\section{Cumplir con las expectativas del cliente}

En la Tabla 32 se puede ver que un 36.9\% (614 personas) contestó de acuerdo en que las personas que le han brindado servicio han cumplido con lo que esperaban, un $32.3 \%$ respondieron en totalmente de acuerdo, un $21.7 \%$ respondieron de forma neutral, un $5.9 \%$ respondieron en desacuerdo, un 2.5\% respondieron en totalmente en desacuerdo, y un $0.7 \%$ no contestaron. Lo anterior nos indica que un $69.2 \%$ están de acuerdo en que las personas que le han brindado servicio han cumplido con lo que esperaban, pero la neutralidad es alta de un $21.7 \%$ lo cual sugiere que se puede mejorar eso a través de la capacitación en una cultura de servicio al cliente.

\begin{tabular}{|c|c|c|c|}
\hline & $\mathrm{f}$ & $\mathrm{p}$ & $\mathrm{p}$ acumulado \\
\hline No contestó & 12 & 0.7 & 0.7 \\
\hline Totalmente en desacuerdo & 41 & 2.5 & 3.2 \\
\hline Desacuerdo & 98 & 5.9 & 9.1 \\
\hline Neutral & 361 & 21.7 & 30.8 \\
\hline De acuerdo & 614 & 36.9 & 67.7 \\
\hline Totalmente de acuerdo & 538 & 32.3 & 100.0 \\
\hline Total & 1664 & 100.0 & \\
\hline
\end{tabular}


Invest. pens. crit.

Vol. 2, No. 4, mayo-agosto 2014.

pp. 4-58

Gráfico 32. Las personas que me han brindado servicio han cumplido con lo que yo esperaba

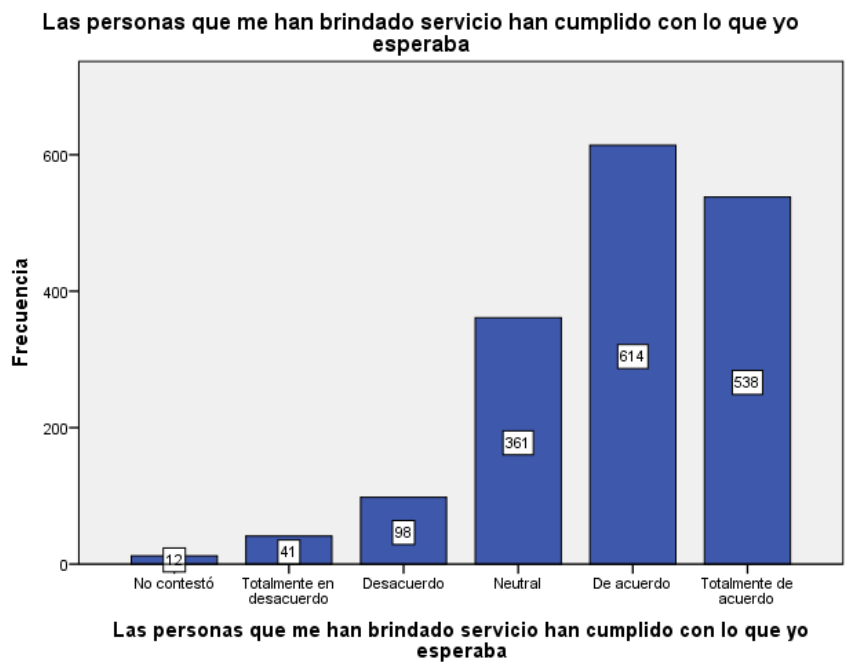

Fuente: Encuesta aplicada a Turistas en la Ciudad de Panamá, en el mes de noviembre de 2013.

\section{Confianza en Panamá}

En la Tabla 33 se puede ver que un 42.7\% (711 personas) contestaron en totalmente de acuerdo en que lo que leyó de Panamá antes de la visita le inspiro confianza, un 34.7\% respondieron en acuerdo, un $16.2 \%$ respondieron de forma neutral, un $4.4 \%$ respondieron en desacuerdo, un $1.6 \%$ respondieron en totalmente en desacuerdo, y un $0.3 \%$ no contestaron. Lo anterior nos indica que un $77.4 \%$ están de acuerdo en que lo que leyó de Panamá antes de la visita le inspiro confianza, pero la neutralidad es de un $16.2 \%$ lo cual sugiere que se puede mejorar ese aspecto.

\begin{tabular}{|c|c|c|c|}
\hline & $\mathrm{f}$ & $\mathrm{p}$ & $\mathrm{p}$ acumulado \\
\hline No contestó & 5 & 0.3 & 0.3 \\
\hline Totalmente en desacuerdo & 27 & 1.6 & 1.9 \\
\hline Desacuerdo & 74 & 4.4 & 6.4 \\
\hline Neutral & 269 & 16.2 & 22.5 \\
\hline De acuerdo & 578 & 34.7 & 57.3 \\
\hline Totalmente de acuerdo & 711 & 42.7 & 100.0 \\
\hline Total & 1664 & 100.0 & \\
\hline
\end{tabular}


Invest. pens. crit.

Vol. 2, No. 4, mayo-agosto 2014.

pp. $4-58$

Gráfico 33. Lo que lei acerca de Panamá antes de mi visita me inspiró confianza

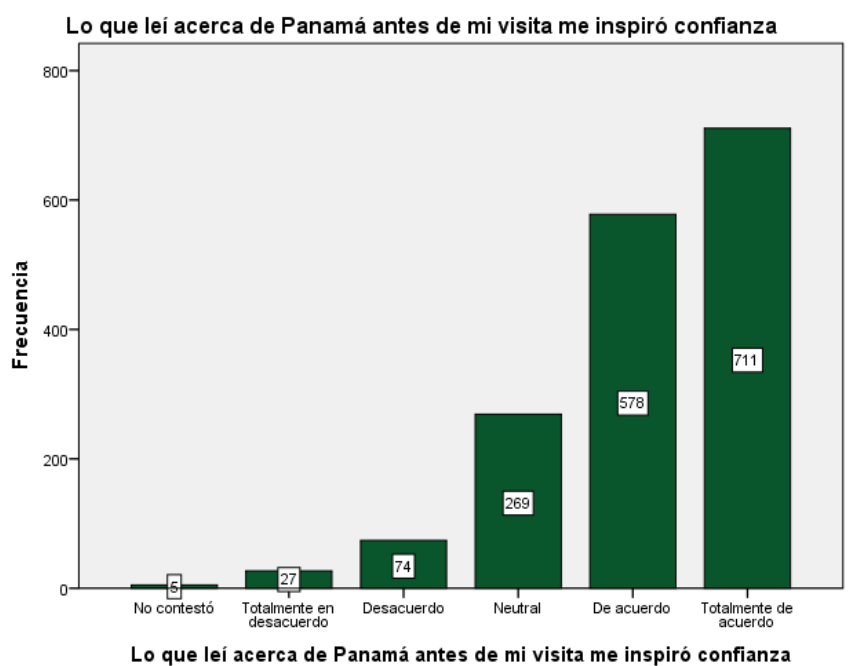

Fuente: Encuesta aplicada a Turistas en la Ciudad de Panamá, en el mes de noviembre de 2013.

\section{Infraestructuras para atender necesidades}

En la Tabla 34 se puede ver que un 38.4\% (639 personas) contestaron en totalmente de acuerdo en que siente que Panamá cuenta son suficiente infraestructuras para atender sus necesidades, un $34.0 \%$ respondieron en acuerdo, un $19.4 \%$ respondieron de forma neutral, un $5.8 \%$ respondieron en desacuerdo, un $1.9 \%$ respondieron en totalmente en desacuerdo, y un $0.5 \%$ no contestaron. Lo anterior nos indica que un $72.4 \%$ están de acuerdo en que siente que Panamá cuenta son suficiente infraestructuras para atender sus necesidades, pero la neutralidad es de un $19.4 \%$ lo cual sugiere que se puede mejorar ese aspecto.

Tabla 34. Lo que leí acerca de Panamá antes de mi visita me inspiró con-

fianza

\begin{tabular}{lccc}
\hline & $\mathrm{f}$ & $\mathrm{p}$ & $\mathrm{p}$ acumulado \\
\hline No contestó & 9 & 0.5 & 0.5 \\
Totalmente en desacuerdo & 31 & 1.9 & 2.4 \\
Desacuerdo & 96 & 5.8 & 8.2 \\
Neutral & 323 & 19.4 & 27.6 \\
De acuerdo & 566 & 34.0 & 61.6 \\
Totalmente de acuerdo & 639 & 38.4 & 100.0 \\
\hline Total & 1664 & 100.0 &
\end{tabular}

Fuente: Encuesta aplicada a Turistas en la Ciudad de Panamá, en el mes de noviembre de 2013. 
Invest. pens. crit.

Vol. 2, No. 4, mayo-agosto 2014.

pp. $4-58$

Gráfico 34. Lo que lei acerca de Panamá antes de mi visita me inspiró confianza

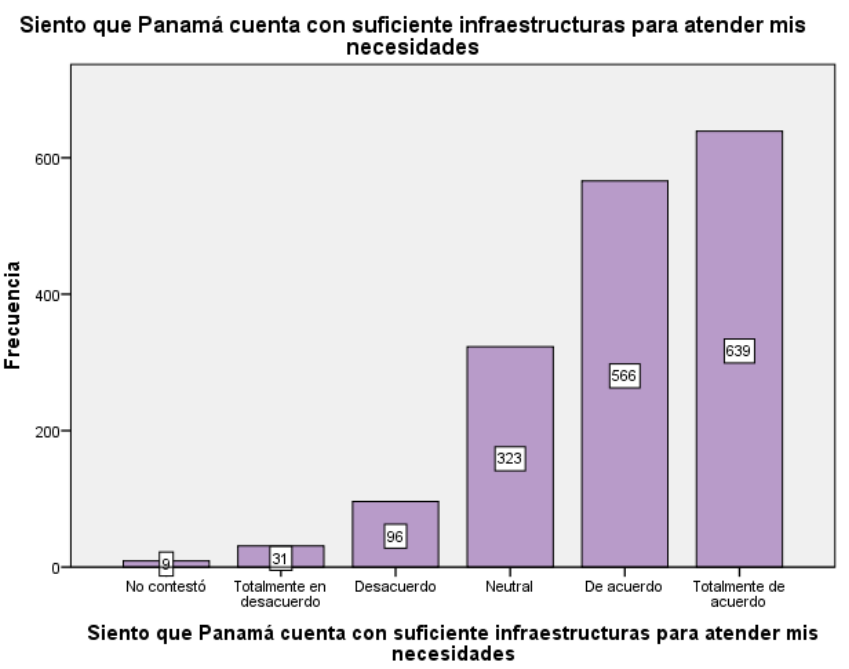

Fuente: Encuesta aplicada a Turistas en la Ciudad de Panamá, en el mes de noviembre de 2013.

\section{Cuartos limpios y agradables}

En la Tabla 35 se puede ver que un 47.9\% (797 personas) contestaron en totalmente de acuerdo en que en los Hoteles encuentran cuartos limpios y ambientes agradables, un $33.1 \%$ respondieron en acuerdo, un 13.9\% respondieron de forma neutral, un 3.8\% respondieron en desacuerdo, un $0.7 \%$ respondieron en totalmente en desacuerdo, y un $0.5 \%$ no contestaron. Lo anterior nos indica que un $81.0 \%$ están de acuerdo en que en los Hoteles encuentran cuartos limpios y ambientes agradables, pero la neutralidad de un $13.9 \%$ refleja que se puede mejorar ese aspecto.

\begin{tabular}{lccc}
\hline \multicolumn{4}{l}{ Tabla 35. En los hoteles encuentro cuartos limpios $y$} \\
\hline & $\mathrm{f}$ & $\mathrm{p}$ & $\mathrm{p}$ p acumulado \\
\hline No contestó & 8 & 0.5 & 0.5 \\
Totalmente en desacuerdo & 12 & 0.7 & 1.2 \\
Desacuerdo & 64 & 3.8 & 5.0 \\
Neutral & 232 & 13.9 & 19.0 \\
De acuerdo & 551 & 33.1 & 52.1 \\
Totalmente de acuerdo & 797 & 47.9 & 100.0 \\
\hline Total & 1664 & 100.0 & \\
\hline
\end{tabular}

Fuente: Encuesta aplicada a Turistas en la Ciudad de Panamá, en el mes de noviembre de 2013.

Fuente: Encuesta aplicada a Turistas en la Ciudad de Panamá, en el mes de noviembre de 2013. 
Invest. pens. crit.

Vol. 2, No. 4, mayo-agosto 2014.

pp. 4-58

Gráfico 35. En los hoteles encuentro cuartos limpios y ambientes agradables

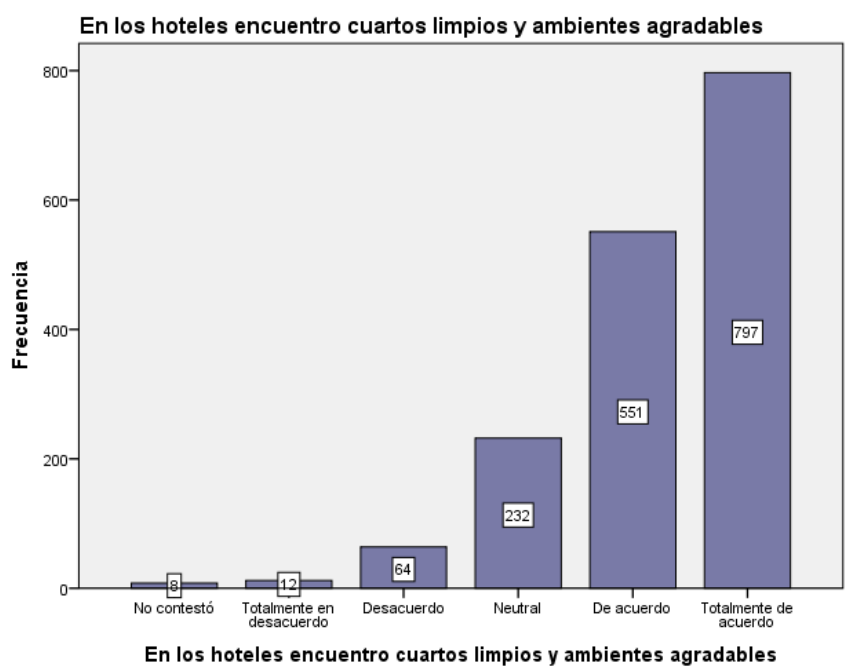

Fuente: Encuesta aplicada a Turistas en la Ciudad de Panamá, en el mes de noviembre de 2013.

\section{Opinión sobre las comidas}

En la Tabla 36 se puede ver que un 46.6\% (775 personas) contestaron en totalmente de acuerdo en que en los restaurantes encontraron buena comida, un $32.2 \%$ respondieron en acuerdo, un $14.3 \%$ respondieron de forma neutral, un $4.1 \%$ respondieron en desacuerdo, un $2.3 \%$ respondieron en totalmente en desacuerdo, y un $0.5 \%$ no contestaron. Lo anterior nos indica que un $78.8 \%$ están de acuerdo en que en los restaurantes encontraron buena comida, pero la neutralidad de un 14.3\% refleja que se puede mejorar ese aspecto.

\begin{tabular}{lccc}
\hline \multicolumn{4}{l}{ Tabla 36. En los restaurantes encuentro buena comida } \\
\hline No contestó & $\mathrm{f}$ & $\mathrm{p}$ & $\mathrm{p}$ acumulado \\
\hline Totalmente en desacuerdo & 9 & 0.5 & 0.5 \\
Desacuerdo & 38 & 2.3 & 2.8 \\
Neutral & 68 & 4.1 & 6.9 \\
De acuerdo & 238 & 14.3 & 21.2 \\
Totalmente de acuerdo & 536 & 32.2 & 53.4 \\
\hline Total & 775 & 46.6 & 100.0 \\
\hline
\end{tabular}

Fuente: Encuesta aplicada a Turistas en la Ciudad de Panamá, en el mes de noviembre de 2013. 
Invest. pens. crit.

Vol. 2, No. 4, mayo-agosto 2014.

pp. $4-58$

Gráfico 36. En los restaurantes encuentro buena comida

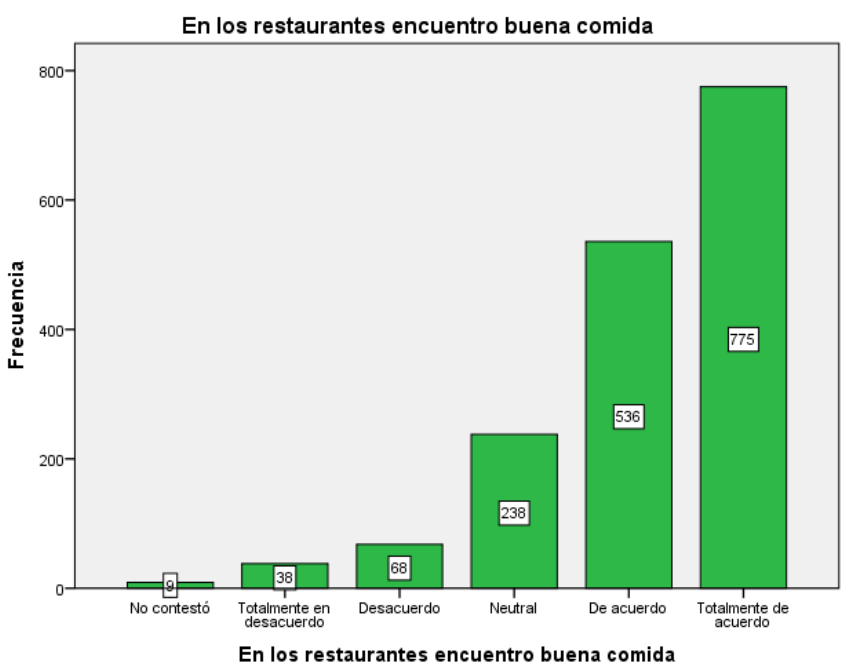

Fuente: Encuesta aplicada a Turistas en la Ciudad de Panamá, en el mes de noviembre de 2013.

\section{$\underline{\text { Cruce de variables relacionadas }}$}

A continuación se hará un cruce de variables relacionadas con la base de datos confeccionada.

De la Tabla 37 podemos decir que hay una neutralidad y desacuerdo fuerte en los visitantes de Europa, en los de América Latina es donde hay más acuerdo en que Panamá es un país acogedor para los visitantes.

\begin{tabular}{|c|c|c|c|c|c|c|c|c|}
\hline \multicolumn{9}{|c|}{ Tabla 37. Tabla de contingencia Origen * Considero que Panamá es un país acogedor para los visitantes } \\
\hline \multirow{2}{*}{$\begin{array}{l}\text { Considero que Panamá } \\
\text { es un país acogedor para } \\
\text { los visitantes }\end{array}$} & \multicolumn{7}{|c|}{ País de origen } & \multirow[b]{2}{*}{ Total } \\
\hline & $\begin{array}{c}\text { No con- } \\
\text { testó }\end{array}$ & $\begin{array}{l}\text { EUA o } \\
\text { Canadá }\end{array}$ & $\begin{array}{c}\text { América } \\
\text { Latina }\end{array}$ & Europa & Asia & $\begin{array}{c}\text { Medio } \\
\text { Oriente }\end{array}$ & Otro & \\
\hline No contestó & 0 & 1 & 0 & 0 & 0 & 0 & 0 & 1 \\
\hline Totalmente en desacuerdo & 0 & 1 & 5 & 1 & 1 & 2 & 7 & 17 \\
\hline Desacuerdo & 0 & 14 & 29 & 15 & 0 & 1 & 5 & 64 \\
\hline Neutral & 8 & 35 & 76 & 47 & 5 & 2 & 6 & 179 \\
\hline De acuerdo & 11 & 103 & 225 & 70 & 15 & 3 & 22 & 449 \\
\hline Totalmente de acuerdo & 25 & 255 & 456 & 112 & 24 & 13 & 69 & 954 \\
\hline Total & 44 & 409 & 791 & 245 & 45 & 21 & 109 & 1664 \\
\hline
\end{tabular}

En la Tabla 38 podemos decir que el totalmente en desacuerdo hacia el respeto en el trato, es mayor en las mujeres (21 personas). 
Invest. pens. crit.

Vol. 2, No. 4, mayo-agosto 2014.

pp. 4-58

Tabla 38. Tabla de contingencia Las personas que me han atendido son respetuosos en el trato conmigo * Genero

\begin{tabular}{lcccc} 
Las personas que me han atendido son respe- & \multicolumn{3}{c}{ Género } \\
\cline { 2 - 4 } \multicolumn{1}{c}{ tuosos en el trato conmigo } & No contestó & Masculino & Femenino & Total \\
No contestó & 0 & 1 & 1 & $\mathbf{2}$ \\
Totalmente en desacuerdo & 10 & 19 & 21 & $\mathbf{5 0}$ \\
Desacuerdo & 2 & 71 & 40 & $\mathbf{1 1 3}$ \\
Neutral & 11 & 210 & 163 & $\mathbf{3 8 4}$ \\
De acuerdo & 26 & 289 & 231 & $\mathbf{5 4 6}$ \\
Totalmente de acuerdo & 32 & 292 & 245 & $\mathbf{5 6 9}$ \\
\hline Total & $\mathbf{8 1}$ & $\mathbf{8 8 2}$ & $\mathbf{7 0 1}$ & $\mathbf{1 6 6 4}$ \\
\hline
\end{tabular}

En la Tabla 39 podemos decir que el totalmente en desacuerdo hacia que las personas les entienden lo que quieren decir, es mayor en las mujeres.

\begin{tabular}{lcccc}
\hline Tabla 39. Tabla de contingencia Las personas que me han brindado servicios entienden lo que les quiero decir * \\
Genero \\
\cline { 2 - 4 } $\begin{array}{l}\text { Las personas que me han brindado servicios } \\
\quad \text { entienden lo que les quiero decir }\end{array}$ & No contestón & Masculino & Femenino & Total \\
No contestó & 0 & 2 & 2 & 4 \\
Totalmente en desacuerdo & 3 & 25 & 26 & $\mathbf{5 4}$ \\
Desacuerdo & 9 & 42 & 48 & $\mathbf{9 9}$ \\
Neutral & 11 & 195 & 137 & $\mathbf{3 4 3}$ \\
De acuerdo & 33 & 334 & 241 & $\mathbf{6 0 8}$ \\
Totalmente de acuerdo & 25 & 284 & 247 & $\mathbf{5 5 6}$ \\
\hline Total & $\mathbf{8 1}$ & $\mathbf{8 8 2}$ & $\mathbf{7 0 1}$ & $\mathbf{1 6 6 4}$ \\
\hline
\end{tabular}

En la Tabla 40 podemos decir que la neutralidad hacia que los han atendido con respeto es más pronunciado entre los que vienen de EUA o Canadá, y la mejor aceptación está en los de América Latina.

Tabla 40. Tabla de contingencia Las personas que me han brindado atendido son respetuosos en el trato conmigo * Pais de origen

\begin{tabular}{|c|c|c|c|c|c|c|c|c|}
\hline \multirow{2}{*}{$\begin{array}{l}\text { Las personas que me han } \\
\text { atendido son respetuosos } \\
\text { en el trato conmigo }\end{array}$} & \multicolumn{7}{|c|}{ País de origen } & \multirow[b]{2}{*}{ Total } \\
\hline & $\begin{array}{l}\text { No con- } \\
\text { testó }\end{array}$ & $\begin{array}{l}\text { EUA o } \\
\text { Canadá }\end{array}$ & $\begin{array}{l}\text { América } \\
\text { Latina }\end{array}$ & Europa & Asia & $\begin{array}{c}\text { Medio } \\
\text { Oriente }\end{array}$ & Otro & \\
\hline No contestó & 0 & 0 & 1 & 0 & 0 & 0 & 1 & 2 \\
\hline Totalmente en desacuerdo & 8 & 9 & 21 & 6 & 2 & 1 & 3 & 50 \\
\hline Desacuerdo & 1 & 21 & 58 & 16 & 4 & 0 & 13 & 113 \\
\hline Neutral & 8 & 103 & 181 & 69 & 10 & 2 & 11 & 384 \\
\hline De acuerdo & 7 & 151 & 255 & 83 & 14 & 10 & 26 & 546 \\
\hline Totalmente de acuerdo & 20 & 125 & 275 & 71 & 15 & 8 & 55 & 569 \\
\hline Total & 44 & 409 & 791 & 245 & 45 & 21 & 109 & 1664 \\
\hline
\end{tabular}

En la Tabla 41 podemos decir que los de ingresos menores, se presentan en los latinos, y los de alto ingreso son proporcionalmente más altos de EUA o Canadá y Europa, y Medio Oriente. 
Invest. pens. crit.

Vol. 2, No. 4, mayo-agosto 2014.

pp. $4-58$

\begin{tabular}{|c|c|c|c|c|c|c|}
\hline \multirow[b]{2}{*}{ País de origen } & \multicolumn{5}{|c|}{ Ingresos } & \multirow[b]{2}{*}{ Tota } \\
\hline & No contestó & $\begin{array}{l}\begin{array}{l}\$ 1,500 \\
\text { o me- } \\
\text { nos }\end{array}\end{array}$ & $\begin{array}{c}\$ 1,501 \text { a } \\
\$ 3,000\end{array}$ & $\begin{array}{c}\$ 3,001 \text { a } \\
\$ 5,000\end{array}$ & $\$ 5,001$ o más & \\
\hline No contestó & 31 & 3 & 6 & 2 & 2 & 44 \\
\hline EUA o Canadá & 39 & 87 & 89 & 110 & 84 & 409 \\
\hline América Latina & 77 & 205 & 195 & 215 & 99 & 791 \\
\hline Europa & 11 & 40 & 42 & 80 & 72 & 245 \\
\hline Asia & 3 & 7 & 12 & 11 & 12 & 45 \\
\hline Medio Oriente & 1 & 5 & 5 & 4 & 6 & 21 \\
\hline Otro & 8 & 27 & 27 & 35 & 12 & 109 \\
\hline Total & 170 & 374 & 376 & 457 & 287 & 1664 \\
\hline
\end{tabular}

En la Tabla 42 podemos decir que la mayor parte de los turistas tienen gastos de entre $\$ 1,001$ y $\$ 5,000$, es similar en casi todas las regiones.

\begin{tabular}{|c|c|c|c|c|c|c|}
\hline \multirow[b]{2}{*}{ País de origen } & \multicolumn{5}{|c|}{ Ingresos } & \multirow[b]{2}{*}{ Total } \\
\hline & No contestó & $\begin{array}{c}\$ 1000 \text { o me- } \\
\text { nos }\end{array}$ & $\begin{array}{c}\text { Entre } \$ 1,001 \\
\text { y } \$ 5,000\end{array}$ & $\begin{array}{c}\text { Entre } \$ 5,001 \\
y \\
\$ 10,000\end{array}$ & $\begin{array}{l}\text { Más de } \\
\$ 10,000\end{array}$ & \\
\hline No contestó & 22 & 8 & 8 & 4 & 2 & 44 \\
\hline EUA o Canadá & 32 & 114 & 176 & 65 & 22 & 409 \\
\hline América Latina & 53 & 247 & 341 & 101 & 49 & 791 \\
\hline Europa & 8 & 59 & 104 & 48 & 26 & 245 \\
\hline Asia & 1 & 10 & 21 & 9 & 4 & 45 \\
\hline Medio Oriente & 1 & 4 & 7 & 7 & 2 & 21 \\
\hline Otro & 7 & 35 & 44 & 7 & 16 & 109 \\
\hline Total & 124 & 477 & 701 & 241 & 121 & 1664 \\
\hline
\end{tabular}

Prueba de hipótesis

La prueba de hipótesis es para determinar si es o no bueno el servicio al cliente que se brinda en Panamá. Para probar la hipótesis se realizó una tabla de contingencias entre las preguntas $\mathrm{N}^{\circ} 18$ y la $\mathrm{N}^{\circ}$ 20. La pregunta 18 trata sobre: La gente de la calle es amable y me ayudó en orientarme o llegar a mis destinos. La pregunta 20 es sobre: Las personas que me han atendido me han dado un buen servicio desde la primera vez.

Hipótesis Nula $(\mathbf{H 0})=$ No hay diferencia estadística significativa en que el servicio al cliente en Panamá no es percibido de forma positiva.

Hipótesis (H1) = Hay diferencia estadística significativa en que el servicio al cliente en Panamá es percibido de forma positiva.

A continuación el cruce de ambas variables. 
Invest. pens. crit.

Vol. 2, No. 4, mayo-agosto 2014.

pp. $4-58$

Tabla 43. Tabla de contingencia La gente de la calle es amable y me ayudó en orientarme o llegar a mis destinos * Las personas que me han atendido me han dado un buen servicio desde la primera vez.

\begin{tabular}{|c|c|c|c|c|c|c|c|c|c|c|c|c|c|}
\hline \multirow{3}{*}{$\begin{array}{c}\text { La gente de la calle es } \\
\text { amable y me ayudó en } \\
\text { orientarme o llegar a } \\
\text { mis destinos }\end{array}$} & \multicolumn{12}{|c|}{$\begin{array}{l}\text { Las personas que me han atendido me han dado un buen servicio desde la primera } \\
\text { vez }\end{array}$} & \multirow{3}{*}{ Total } \\
\hline & \multicolumn{2}{|c|}{ No contestó } & \multicolumn{2}{|c|}{$\begin{array}{c}\text { Totalmente } \\
\text { en } \\
\text { desacuerdo }\end{array}$} & \multicolumn{2}{|c|}{ Desacuerdo } & \multicolumn{2}{|c|}{ Neutral } & \multicolumn{2}{|c|}{ De acuerdo } & \multicolumn{2}{|c|}{$\begin{array}{l}\text { Totalmente } \\
\text { de acuerdo }\end{array}$} & \\
\hline & n & $\%$ & $\mathbf{n}$ & $\%$ & $\mathbf{n}$ & $\%$ & n & $\%$ & $\mathbf{n}$ & $\%$ & $\mathbf{n}$ & $\%$ & \\
\hline No contestó & 0 & 0.0 & 0 & 0.0 & 0 & 0.0 & 2 & 0.1 & 3 & 0.2 & 4 & 0.2 & 9 \\
\hline Totalmente en desacuerdo & 0 & 0.0 & 23 & 1.4 & 13 & 0.8 & 8 & 0.5 & 6 & 0.4 & 5 & 0.3 & 55 \\
\hline Desacuerdo & 2 & 0.1 & 14 & 0.8 & 32 & 1.9 & 49 & 2.9 & 20 & 1.2 & 8 & 0.5 & 125 \\
\hline Neutral & 1 & 0.1 & 11 & 0.7 & 39 & 2.3 & 136 & 8.2 & 145 & 8.7 & 57 & 3.4 & 389 \\
\hline De acuerdo & 0 & 0.0 & 7 & 0.4 & 22 & 1.3 & 138 & 8.3 & 230 & 13.8 & 156 & 9.4 & 553 \\
\hline Totalmente de acuerdo & 3 & 0.2 & 4 & 0.2 & 13 & 0.8 & 59 & 3.5 & 132 & 7.9 & 322 & 19.4 & 533 \\
\hline Total & 6 & 0.4 & 59 & 3.5 & 119 & 7.2 & 392 & 23.6 & 536 & 32.2 & 552 & 33.2 & 1664 \\
\hline
\end{tabular}

Se realizó una prueba de Chi cuadrado para ver la significancia estadística de los datos. Es decir, queremos ver si existen diferencias significativas en los grupos. A continuación la prueba de Chi cuadrado

\begin{tabular}{lccc}
\hline Tabla 44. Prueba de chi-cuadrado & & \\
\hline & Valor & gl & $\begin{array}{c}\text { Sig. asintótica } \\
\text { (bilateral) }\end{array}$ \\
Chi-cuadrado de Pearson & $704.687^{\text {a }}$ & 25 & .000 \\
Razón de verosimilitudes & 538.381 & 25 & .000 \\
Asociación lineal por lineal & 375.560 & 1 & .000 \\
N de casos válidos & 1664 & & \\
\hline a 14 casillas (38.9\%) tienen una frecuencia esperada inferior a 5. \\
La frecuencia mínima esperada es .03
\end{tabular}

La prueba de Chi cuadrado presenta una significancia de .000 , la regla de decisión dice que si la significancia es menor .05 se rechaza la hipótesis nula, y si es mayor se acepta; como en este caso es de .000 se rechaza la hipótesis nula.

La prueba Chi cuadrado muestra una significancia de .00, quiere decir que se rechaza que no existe diferencia estadísticamente significativa de los grupos en que el servicio al cliente en Panamá es percibido de forma positiva, ya que si vemos el cuadro de contingencias vemos que hay diferencias, dado que hay más respuestas hacia lo de acuerdo y totalmente de acuerdo.

Esto nos lleva a rechazar la hipótesis nula de que no hay hay diferencia estadística significativa en que el servicio al cliente en Panamá es percibido de forma positiva.

Si vemos la tabla de contingencias anterior vemos que las respuestas de acuerdo hacia un servicio amable y un buen servicio es de un 65.2\% (33.2\% más un 32.0\%). Lo anterior indica que existe una diferencia de $34.8 \%$ que se debe mejorar, lo cual nos lleva a pensar en acciones necesarias para fomentar un mejor servicio al cliente en nuestro país: Panamá. 
Invest. pens. crit.

Vol. 2, No. 4, mayo-agosto 2014.

pp. $4-58$

\section{Discusión de resultados}

En la Tabla 45 podemos ver la suma de las respuestas de acuerdo hacia las preguntas relacionadas con las infraestructuras para el turismo. El promedio de las 12 preguntas es de 70.0.

\begin{tabular}{lc}
\hline Tabla 45. Servicio al cliente & \\
\hline \multicolumn{1}{c}{ Pregunta } & Porcentaje de respuestas de acuerdo \\
\hline Panamá como país acogedor & 84.3 \\
Servicios e instalaciones en el Aeropuerto & 72.8 \\
Transporte público y selectivo & 48.4 \\
Transporte especializado & 71.4 \\
Experiencia en hospedajes en hoteles y pensiones & 78.3 \\
Experiencia en los restaurantes & 72.3 \\
Experiencias al hacer compras en Panamá & 76.5 \\
Experiencia en visitas a lugares turísticos & 78.0 \\
Experiencia en percibir aspectos culturales & 72.8 \\
Opinión sobre los servicios de telecomunicaciones & 77.7 \\
Opinión sobre las calles y transporte & 44.5 \\
Cumplimiento de los objetivos de negocios & 63.6 \\
\hline \multicolumn{2}{c}{ Promedio } \\
\hline \multicolumn{2}{c}{}
\end{tabular}

Si llevamos esto al campo académico, podemos decir que no se marca como bueno en esos aspectos, dado que para tener una calificación de bueno se debe tener un puntaje de 81, y si vemos en la gráfica siguiente sólo en un punto se marca como bueno y es lo referente a que Panamá es un país acogedor (84.3). El segundo aspecto de mayor puntaje es la experiencia en hospedajes en hoteles y pensiones, y esto es así porque Panamá tiene una buena infraestructura hotelera.

En todos los otros aspectos la sumatoria no llega a 81. Lo anterior denota que se deben tomar acciones en el país para mejorar las infraestructuras que utilizan los turistas. Los factores que muestran menos aceptación o calificaciones más bajas son las opiniones sobre las calles y transporte, y sobre el transporte público y selectivo.

En cuanto las calles y transportes, esto es así porque como sabemos se hacen múltiples construcciones en las vías panameñas y se seguirá haciendo otras como lo son la línea 3 del Metro que va desde la terminal de Albrook hasta la Ciudad del Futuro en Arraiján próximo a La Chorrera.

En cuanto a los transportes públicos y selectivos, podemos ver que en Panamá los taxis no son selectivos sino colectivos, y generalmente en otros países eso no es común. 
Invest. pens. crit.

Vol. 2, No. 4, mayo-agosto 2014.

pp. $4-58$

Gráfico 37. Infraestructura para el turismo

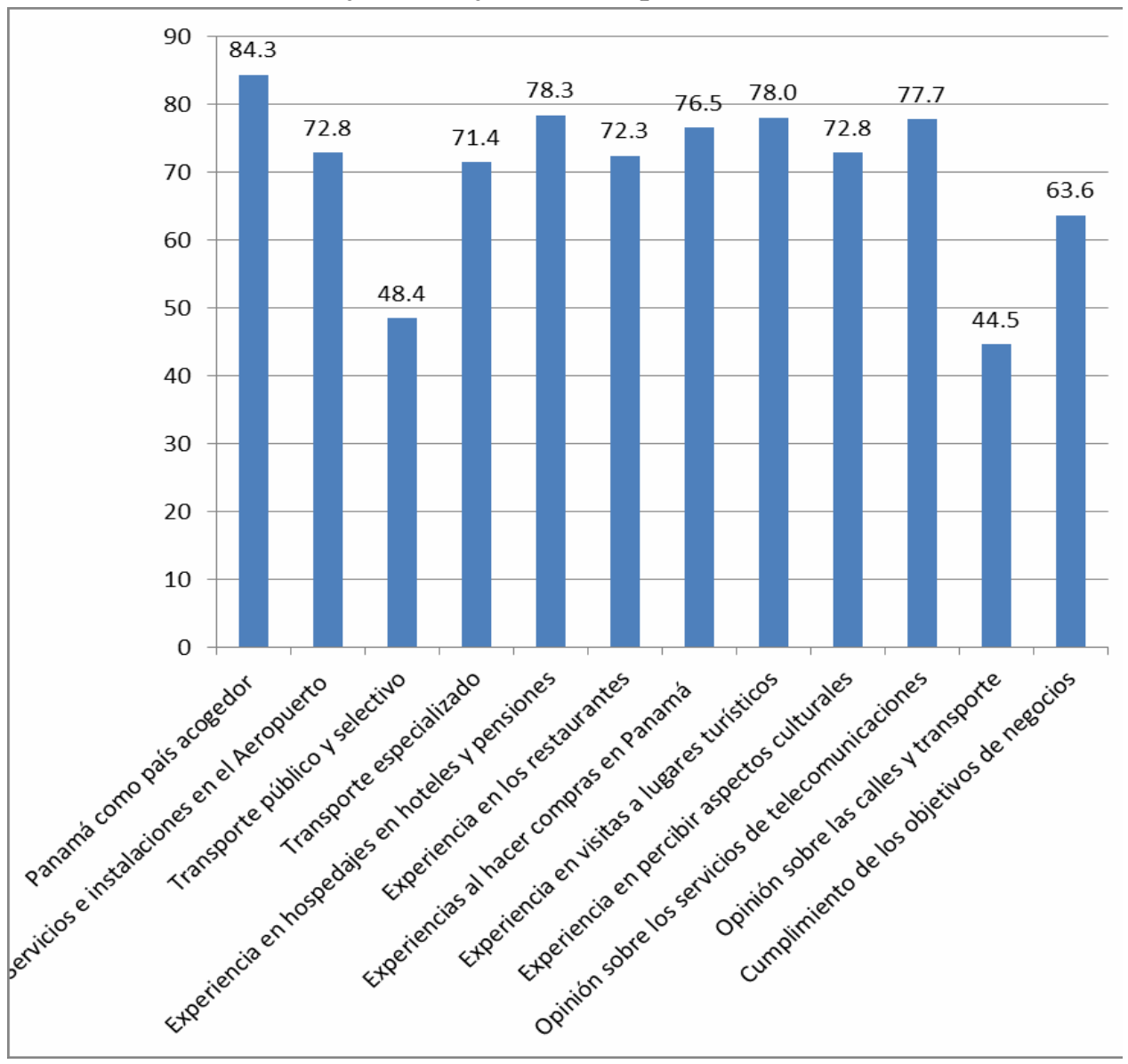

En la Tabla 46 podemos ver la suma de las respuestas de acuerdo hacia las preguntas relacionadas con el servicio al cliente. El promedio de las 13 preguntas es de 70.5. 
Invest. pens. crit.

Vol. 2, No. 4, mayo-agosto 2014.

pp. $4-58$

\begin{tabular}{lc}
\hline Tabla 46. Servicio al cliente & \\
\hline \multicolumn{1}{c}{ Pregunta } & Porcentaje de respuestas de acuerdo \\
\hline Seguridad en la estadía & 76.3 \\
Me entienden lo que quiero decir & 69.9 \\
Entienden mis necesidades & 64.5 \\
Respeto en el trato & 67.0 \\
Interés en el servicio & 64.0 \\
Amabilidad de la gente & 65.2 \\
Atención a tiempo & 65.8 \\
Me han brindado un buen servicio & 65.4 \\
Cumplir con las expectativas del cliente & 69.2 \\
Confianza en Panamá & 77.4 \\
Infraestructuras para atender necesidades & 72.4 \\
Cuartos limpios y agradables & 81.0 \\
Opinión sobre las comidas & 78.8 \\
\hline \multicolumn{2}{c}{ Promedio } \\
\hline
\end{tabular}

En el cuadro anterior sólo en un punto se marca como bueno y es lo referente a los cuartos limpios y agradables (81.0). El segundo aspecto de mayor puntaje es la opinión positiva hacia las comidas. Panamá cuenta con buenos hoteles con habitaciones adecuadas para los turistas. Además, tienen diversos restaurantes para las diversas culturas y regiones del mundo.

En todos los otros aspectos la sumatoria no llega a 81. Lo anterior denota que se deben tomar acciones en el país para mejorar el servicio al cliente que se brinda a los turistas. Los factores que muestran menos aceptación o calificaciones más bajas son el interés por prestar un buen servicio y el entendimiento de las necesidades de los clientes.

En cuanto al interés por un buen servicio, denota la poca capacitación que tienen las personas para reconocer la importancia del servicio al cliente. Por otro lado, en cuanto al entendimiento de las necesidades de los clientes, puede ser por el poco dominio del idioma inglés por parte de las personas que atienden a los clientes. 
Invest. pens. crit.

Vol. 2, No. 4, mayo-agosto 2014.

pp. $4-58$

Gráfico 38. Servicio al cliente

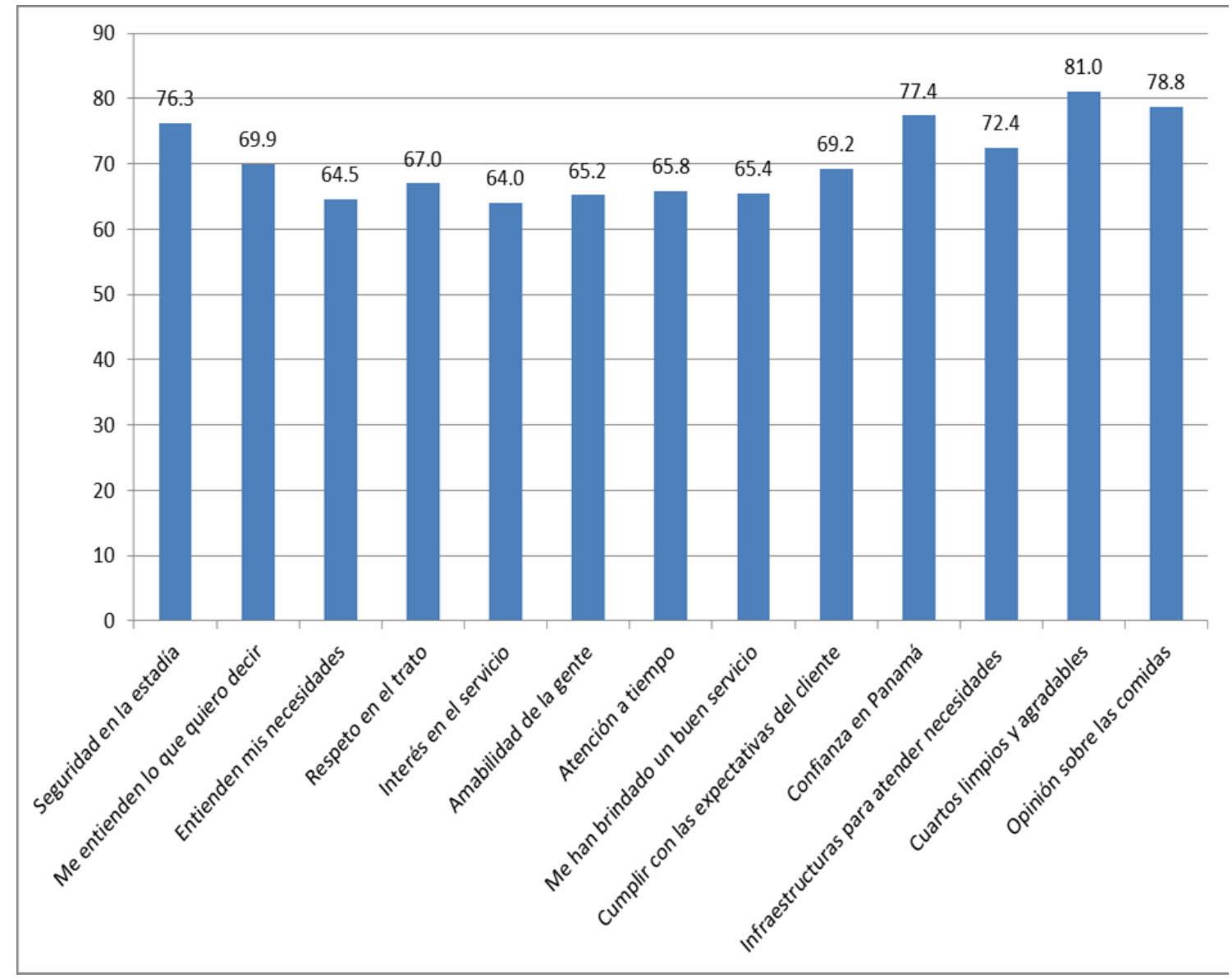

\section{Conclusiones}

A manera de conclusiones podemos plantear lo siguiente:

1. Se encuestó a un total de 1664 turistas en la Ciudad de Panamá, un el 53.0\% eran del sexo masculino, y un $42.1 \%$ eran del sexo femenino, el 36.2\% tenían edades entre 21 a 35 años, como la edad más representativa, la mayoría un 47.5\% eran de América Latina y un 42.1\% gastaron entre $\$ 1,001$ y $\$ 5,000$.

2. Un $45.4 \%$ de los turistas manifestaron que su motivo de viaje era de placer, el $36.4 \%$ dicen que han realizado entre 2 a 4 visitas al país, un 57.3\% (954 personas) contestaron que estaban totalmente de acuerdo en que Panamá es un país acogedor para los visitantes.

3. Un $72.8 \%$ muestran acuerdo en que los servicios e instalaciones en el aeropuerto al llegar o salir son buenos, pero hay que mejorar ese aspecto porque hay un $20 \%$ neutrales y existe un desacuerdo del $6.5 \%$.

4. Los turistas en un $48.4 \%$ muestran acuerdo en que el transporte público y selectivo en Panamá es adecuado, pero es un puntaje muy bajo, por otro lado un $71.4 \%$ están de acuerdo 
Invest. pens. crit.

Vol. 2, No. 4, mayo-agosto 2014.

pp. 4-58

en que el transporte especializado para el turismo son cómodos, pero aún se puede mejorar con el fin de reducir las respuestas neutrales.

5. Los turistas indican que un $78.3 \%$ de acuerdo en que la experiencia durante el hospedaje en hoteles y pensiones es buena, y un $72.3 \%$ de los turistas están de acuerdo en que la experiencia con los restaurantes y lugares de comida es agradable.

6. Un $78.0 \%$ de los encuestados están de acuerdo en que la experiencia en visitas a lugares turísticos es atractiva, y un $76.5 \%$ de acuerdo en que la experiencia en hacer compras en Panamá es favorable.

7. Un $64.5 \%$ están de acuerdo en que las personas que le han brindado servicios entienden las necesidades como visitante, y un 81.0\% están de acuerdo en que en los Hoteles encuentran cuartos limpios y ambientes agradables.

8. La prueba de Chi cuadrado nos lleva a aceptar la hipótesis Hi: Hay diferencia estadística significativa en que el servicio al cliente en Panamá es bueno, sin embargo nos falta mejorar muchos aspectos de infraestructuras y de servicio al cliente.

\section{Referencias}

Echeverry, R. (2006). Dirección estrategia de marketing. Asunción, Paraguay: Universidad Americana.

Hernández, R.; Fernández, C.; y Baptista, P. (2010). Metodología de la Investigación. 5ta edición. Editora México: McGraw-Hill.

Junta de Andalucía. Manual calidad del servicio y atención al cliente. España, 2010.

Kerlinger, F. y Lee, H. (2002). Investigación del comportamiento: Métodos de investigación de ciencias sociales. México: McGraw-Hill.

Kotler, P. y Lane, K. (2006). Dirección de marketing. 12ª edición. México: Editorial Pearson.

Larrea, P. (2008). Calidad de servicio: del marketing a la estrategia. España: Ediciones Díaz de Santos.

Manual del usuario del sistema básico de IBM SPSS Statistics 20. Recuperado de: ftp://public.dhe.ibm.com/software/analytics/spss/documentation/statistics/20.0/es/cl ient/Manuals/IBM_SPSS_Statistics_Core_System_Users_Guide.pdf

Pérez, C. (2007). Técnicas estadísticas con SPSS. España: Prentice-Hall. 
Invest. pens. crit.

Vol. 2, No. 4, mayo-agosto 2014.

pp. $4-58$

\section{Encuesta utilizada en idioma español}

\section{USMA +}

\section{Encuesta sobre calidad servicio al cliente en Panamá}

Hola, mi nombre es: $\frac{\text { Soy un estudiante de la Universidad Católica Santa María la Antigua. Estamos llevando a cabo }}{\text { un interesante estudio para conocer su percepción sobre la calidad del servicio al cliente que está récibiendo como visitante en Panamá }}$
por parte de algunas instituciones públicas y privadas. Esta encuesta no tomara más de 10 minutos de su de su tiempo. Nuestro
objetivo es obtener información que nos llevará a mejorar la calidad del servicio al cliente a los visitantes de nuestro país. Gracias
de antemano por su cooperación. Empecemos.

\section{Experiencia general de servicio al cliente}

En una escala del 5 al 1 , en donde $5=$ estoy totalmente de acuerdo y $1=$ estoy totalmente en desacuerdo, señale el grado en que las siguientes aseveraciones describen su experiencia con el servicio al cliente recibido durante su visita a Panamá. Indique su nivel de percepción aún a pesar de no tener experiencia personal directa en algún punto

1. Considero que Panamá es un país acogedor para los visitantes.

Servicios e instalaciones en el aeropuerto al llegar o al salir son buenos ....

Transporte público y selectivo en Panamá (taxis, buses) es adecuado.

Transporte especializado para el turismo son comodos.

Experiencia durante el hospedaje en hoteles y pensiones es buena

Experiencia con los restaurantes y lugares de comida es agradable

Experiencia en hacer compras en Panamá (como turista) es favorable.

Experiencia en visitas a lugares turisticos es atractiva.

Experiencia en percibir aspectos culturales sobre Panamá es positiva

10. Servicios de telecomunicaciones (incluye acceso a Internet) es buena

11. Infraestructura de calles, transporte y tráfico en general es buena.....

12. Logré completar mis objetivos de negocios (si aplica) de forma exitosa

13. Me siento seguro durante la estadia de mi visita a Panamá

14. Las personas que me han brindado servicios entienden lo que les quiero decir

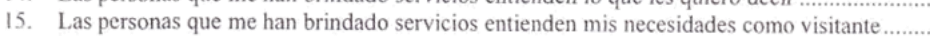

16. Las personas que me han atendido son respetuosos en el trato conmigo

17. Cuando he necesitado algún servicio me han mostrado interés sincero en solucionarlo ...........

18. La gente de la calle es amable y me ayudó en orientarme o llegar a mis destinos.

19. He sido atendido a tiempo en mis necesidades relacionados a mi visita.

20. Las personas que me han atendido me han dado un buen servicio desde la primera vez

21. Las personas que me han brindado servicio han cumplido con lo que yo esperaba.....

22. Lo que leí acerca de Panamá antes de mi visita me inspiró confianza.

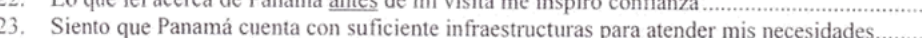

24. En los hoteles encuentro cuartos limpios y ambientes agradables

25. En los restaurantes encuentro buena comida

¿Qué recomendación nos daría para mejorar la calidad del servicio al cliente en Panamá? (Favor contestar atrás)

\section{Datos generales del encuestado}

\begin{tabular}{|c|c|c|}
\hline dad: $\square 20$ o menos $\square 21$ a $35 \square 36$ a $50 \square 51$ a $65 \square$ más de 65 & Género: $\begin{array}{r}\square \text { Masculino } \\
\square \text { Femenino }\end{array}$ & $\begin{array}{l}\text { Usted vino: } \square \text { Solo yo } \\
\square 2 \text { a } 4 \quad \square \text { so más }\end{array}$ \\
\hline $\begin{array}{l}\text { Jivel de educación: } \\
\square \text { Bachillerato } \\
\square \text { Universitario completo } \square \text { Maestría completa } \square \text { Doctorado } \\
\square \text { Otro (indique): }\end{array}$ & \multicolumn{2}{|c|}{$\begin{array}{l}\text { Cuánto se ha gastado en último viaje (excluye pasaje) } \\
\square \$ 1,000 \text { menos } \square \text { Entre } \$ 1,001 \text { y } \$ 5,000 \quad \square \\
\text { Entre } \$ 5,001 \text { y } \$ 10,000 \quad \square \text { Más de } \$ 10,000\end{array}$} \\
\hline $\begin{array}{l}\text { otivo de la visita: } \square \text { Placer } \square \text { Negocio } \square \text { Personal } \square \text { Combinado } \\
\text { Otro motivo (indique): }\end{array}$ & \multirow{2}{*}{\multicolumn{2}{|c|}{$\begin{array}{l}\text { Número total de visitas que ha realizado a Panamá } \\
\square 1 \quad \square 2 \text { a } 4 \quad \square 5 \text { a } 10 \quad \square \text { más de } 10 \\
\text { Ingresos mensuales familiares: } \square \$ 1,500 \text { o menos } \\
\square \$ 1,500 \text { a } \$ 3,000 \quad \square \$ 3,001 \text { a } \$ 5,000 \quad \square \$ 5,001 \text { o } \\
\text { mas }\end{array}$}} \\
\hline $\begin{array}{l}\text { ais de origen: } \square \text { EUA o Canadả } \square \text { América Latina } \square \text { Europa } \\
\text { IAsia } \square \text { Medio oriente } \square \text { Otro (indique): }\end{array}$ & & \\
\hline
\end{tabular}

